\title{
Masonry compression: a numerical investigation at the meso-level
}

Keywords Masonry compression, Material micro-structure, Particle model, Non-linear interface elements.

Abstract The analysis of masonry assemblages under compression using detailed modelling strategies in which units and mortar are modelled separately is a challenging task. Sophisticated standard non-linear continuum models, based on plasticity and cracking, are widely available to represent the masonry components but such models overestimate the experimental strength of masonry prisms under compression. Alternative modelling approaches are therefore needed. This paper focuses on the discussion and detailed analysis of a particle model consisting in a phenomenological discontinuum approach to represent the micro-structure of units and mortar. The micro-structure attributed to the masonry components is composed by linear elastic particles of polygonal shape separated by non-linear interface elements. All the inelastic phenomena occur in the interfaces and the process of fracturing consists of progressive bond-breakage. Clear advantages have been shown by the particle model, when compared to standard continuum models. 


\section{INTRODUCTION}

The compressive behaviour of masonry is of crucial importance for design and safety assessment purposes, since masonry structures are primarily stressed in compression. The present approach in codes, e.g. (CEN, 2003) and (ACI, 2004), is to make the compressive strength of the masonry composite dependent of the compressive strength of the masonry components (units and mortar). This empirical approach is obviously conservative and results from the envelope of a large set of experimental tests, meaning that the compressive strength of masonry can be severely underestimated. The solution today is to carry out a series of tests in expensive wallets (CEN, 1998), which is hardly feasible for all possible masonry materials. In addition, existing code formulas are clearly not applicable to irregular or rubble masonry, which is generally the case of historical masonry structures.

Continuum and discontinuum approaches to model masonry components can be used with the aim of reproducing the experimental behaviour of the masonry composite under compression. Micro-modelling strategies are indeed powerful tools for analysing the basic phenomena occurring in masonry assemblages upon increasing loading, see e.g. (Lourenço and Rots, 1997). For the case of masonry under uniaxial compression, some authors indicate that standard continuum finite element micro-models, based on plasticity and cracking, are capable of obtaining an adequate response of the masonry composite, introducing the behaviour of masonry components, e.g. (Brencich and Gambarotta, 2005) and (Roman and Gomes, 2004). But similar simulations carried out by (Pina-Henriques and Lourenço, 2003) demonstrated otherwise. In fact, it was shown that continuum finite element micro-models largely overestimate the experimental strength and peak strain of masonry prisms tested in compression. Values of 
approximately $170 \%$ were found for the ratio between the predicted and the experimental strengths. As a result, alternative discontinuum modelling approaches that consider the micro-structure of quasi-brittle materials are therefore needed to study the uniaxial compressive behaviour of masonry.

Several advanced computational approaches are currently available for structural analysis developed in discontinuum frameworks, including the finite element method with interface elements, discrete element methods and lattice models. For an exhaustive discussion on the numerical methods available the reader is referred to (Jing, 2003). The finite element method with interface elements is well established and advanced solution procedures are available, (Gens et al., 1988) and (Rots and Schellekens, 1990). For simple geometries under symmetric loading or when the crack path is known in advance from experiments, interface elements can be embedded in the finite element mesh along expected crack paths, (Rots, 1988). If the crack pattern is not known in advance, expensive remeshing techniques, (Ingraffea and Saouma, 1985), or approaches where a sufficient number of interface elements are included in the mesh to account for potential crack paths, (Carol et al., 2001), may be adopted. Typical applications of interface elements in the finite element analysis of masonry structures are the modelling of cracking, slipping or crushing planes, like unit-mortar interfaces or potential cracks in the units, see (Lotfi and Shing, 1994) and (Lourenço and Rots, 1997).

The last decades have witnessed a growing interest of the scientific community in the development of discrete element methods due to the capabilities of such methods to deal with discrete media. Within the most popular discrete element methods, the distinct element method pioneered by (Cundall, 1971) and the discontinuous deformation analysis originally developed by (Shi, 1988) may be distinguished. As can be gathered from the literature, discrete element methods have been widely used to analyse the 
response of blocky assemblages, especially in the field of rock mechanics although references can also be found for blocky masonry structures, (Lemos, 2001). Discrete element methods have also been used by the research community to model the microstructure of granular and brittle disordered materials such as concrete, and examples can be found in (Lorig and Cundall, 1987) and (Vonk, 1993). The rigid-body spring network model has common features with the referred approaches, subdividing the material into a collection of rigid bodies interconnected by zero-size springs, see (Bolander et al., 2000).

Another discontinuum approach that has been receiving vivid attention is lattice models. Its main concept is the discretization of the continuum into a framework of beam or truss elements. Generally, a regular or random triangular lattice of beam elements is adopted, being the size of the beams adjusted so that the elastic stiffness and Poisson's ratio of the complete lattice resemble the values of the continuum. The simulation consists in a set of linear elastic analyses, each one corresponding to a load step. At the end of each load step, the adopted failure law is evaluated and the elements falling in its range are removed from the lattice. Lattice models have been extensively utilized in the study of tensile fracture propagation and references can be found in (Schlangen, 1993), (Van Mier et al., 1995), (Bazant and Planas, 1998) and (Van Vliet, 2000). Recently, a lattice-type model has been proposed by (Cusatis et al., 2003) aiming at a correct simulation of both tensile and compressive fracture processes, as well as three-dimensional effects. In reality, failure of masonry and other cohesivefrictional materials typically involves in-plane splitting cracks or spalling, meaning that 2D models are usually phenomenological and approximate.

In the present paper, a particle 2D model consisting in a phenomenological discontinuum approach based on the finite element method including interface elements 
is proposed to represent the micro-structure of units and mortar, attempting to reproduce adequately the compressive behaviour of masonry. Comparative analyses with experimental results and with numerical results using a continuum model are presented.

\section{MODEL CONCEPT}

\section{Outline of the model}

The proposed particle model is developed on a finite element framework. The discontinuous nature of the masonry components is considered by giving a fictitious micro-structure to units and mortar, which is composed by linear elastic continuum elements of polygonal shape (hereafter named particles) separated by non-linear interface elements. All the inelastic phenomena occur in the interfaces and the process of fracturing consists of progressive bond-breakage. This is, of course, a phenomenological approach able, nevertheless, to capture the typical failure mechanisms and global behaviour of quasi-brittle materials.

Three-noded plane stress triangular elements with a one-point Gauss integration scheme were utilized to model the particles. It is noted that the fracture process controls failure and the differences between plane stress and plane strain are, therefore, negligible. For the interfaces, four-noded line interface elements with zero thickness were adopted. A high dummy stiffness was given to the interface elements to avoid interpenetration of the particles, as it is clear that the amount of penetration is higher with decreasing interface stiffness. Stiffness values ranging from $1 \times 10^{4}$ to $1 \times 10^{5} \mathrm{~N} / \mathrm{mm}^{3}$ were chosen so that overlapping of neighbouring particles would be negligible. (Rots, 1988) and (Schellekens, 1992) reported that beyond stiffness values of 
$1 \times 10^{3} \mathrm{~N} / \mathrm{mm}^{3}$, the application of the Gauss integration scheme leads to oscillatory results. To overcome such deficiency, a two-point Lobatto integration scheme was used.

The constitutive model used for the interface elements was formulated by (Lourenço and Rots, 1997) and is implemented in the finite element code adopted for the analyses (DIANA, 2003). The model includes a tension cut-off for tensile failure (mode I), a Coulomb friction envelope for shear failure (mode II) and a cap mode for compressive failure. Exponential softening is present in all three modes and is preceded by hardening in the case of the cap mode.

The dilatancy angle measures the uplift upon shearing. Dilatancy tends to zero with increasing plastic shear slipping or increasing normal confining pressure. These phenomena occur often combined because shear slip with dilatancy necessarily induces normal compressive stresses. The analyses here reported were performed in a nonassociated plasticity context, assuming a dilatancy equal to zero. In such way, a particle can slide over the other without producing any normal displacement. Non-zero dilatancy associated with the symmetry boundary conditions adopted in the simulations could induce high normal stresses and locking of the particles, resulting in increasing strength. Also for unit-mortar interfaces, (Lourenço and Rots, 1997) recommend a value of zero for the dilatancy angle.

It is noted that the adopted model and the original Hillerborg (Adicionar referência) model for tensile fracture are meant for straight cracks at macro-level. The proposed particle model uses such approach at the meso-level with random particles, which always render tortuous fracture paths. Therefore, the usage of a "macro" fracture energy or "macro" dilatancy angle, for example, seem like a conflict. Nevertheless, the proposed approach, partly similar to the work of Vonk (ano), is rather different from 
other authors (van Mier, Bolander, etc...) that try to capture the response mostly by disorder. It is a phenomenological approach not rooted in a real microstructure.

\section{Mesh construction}

A computer routine has been written to generate the particles, see Figure 1 . As input data, the boundaries of the surface to mesh, the average size of the particles and a distortion factor $D F$, which controls the irregularity of the particles shape, must be given. In addition, the type and average size of the finite elements utilized must be specified. The discretization of the continuum into particles is based on the Voronoi diagram. The Voronoi diagram is a collection of regions that divide space according to a set of given points (nuclei). Each region has a polygonal convex shape and corresponds to one nucleus. All the points in one region are closer to the corresponding nucleus than to any other nucleus. To obtain the coordinates of the vertices of the Voronoi regions, the routine executes a call to an external freeware DOS program named (QHULL, 2001) and then processes the output data.

\section{take in Figure 1}

\section{Material heterogeneity}

In heterogeneous materials the disorder of the material properties at the microlevel is a key issue in the fracture process. In the present model, material disorder is given by attributing to each particle and interface random material properties. For this purpose, values for the elastic modulus $E$ of the particles and for the strength parameters 
of the interfaces (tensile strength $f_{t}$, cohesion $c$ and friction coefficient $\tan \phi$ ) were generated according to a Gaussian distribution. A lower threshold, equal to zero, and an upper threshold, equal to two times the average value have been imposed for each parameter. It is noted, as an example, that for a Gaussian distribution with a coefficient of variation of $50 \%$, the probability to generate a value beyond the referred thresholds is $5 \%$.

\section{MODEL RESPONSE. ELEMENTARY TESTS}

\section{Model utilized}

Elementary tests were carried out resorting to 2D simulations of $100 \times 100 \mathrm{~mm}^{2}$ specimens in order to provide insight into the behaviour of the proposed model. Since cracks are constrained to follow particle boundaries, the influence of particle size and regularity in the mesh configuration must be investigated. For this purpose, three different values for the distortion factor $D F$ were considered (0, 0.3 and 0.6$)$ and, for each value, three different levels for the mesh refinement $M R$ were assumed (denoted by $n, 2 n$ and $4 n$, and associated with an element size one-half and one-fourth of the original size $n$ ), see Figure 2. Given the random nature of the model, for each combination DF$M R$, three analyses were performed using different randomly generated meshes.

take in Figure 2

In-plane symmetry conditions have been adopted, carrying out the simulations as if the specimen was part of a larger portion. Hence, specimen boundaries remain 
straight during the analysis, aiming at reproducing macro homogeneous boundary conditions. In all simulations, the nonlinear system of equations following from the finite element discretization was solved with an incremental-iterative globally convergent Newton-Raphson method with arc-length control and line-search technique.

The same material properties were given to all specimens, so that only the influence of the micro-structure geometry would be assessed. The elastic properties attributed to the particles (elastic modulus $E$ and coefficient of Poisson $v$ ) and to the interfaces (normal modulus $k_{n}$ and shear modulus $k_{s}$ ) are given in Table I, in terms of the average values and corresponding coefficients of variation $C V$. The inelastic properties of the interfaces are shown in Table II. Here, $f_{t}$ is the tensile strength, $G_{f I}$ is the mode I fracture energy, $c$ is the cohesion, $G_{f I I}$ is the mode II fracture energy and $\tan \phi$ is the friction coefficient.

\section{take in Table I and Table II}

A unitary value was assumed for the tensile strength and the cohesion was obtained according to $c=1.5 f_{t}$. This relation was proposed by (Lourenço, 1996) for unit-mortar interfaces. For $G_{f I}$, a value in agreement with the results obtained by (Van der Pluijm, 1999) was adopted and for $G_{f I I}$ a value about five times higher the value proposed by (Lourenço, 1996) for unit-mortar interfaces $(0.1 c)$ was used. The friction coefficient was chosen so that the ratio between the specimen compressive and tensile strengths was about ten, which is a ratio often found for masonry units, see (Schubert, 1988). Given the fact that the approach here followed is phenomenological and not physical, the values adopted for the coefficient of variation of the different 
material parameters are not related with their experimental variability but were chosen so that the overall response of the model resembles the experimental response.

\section{Compressive uniaxial behaviour}

The specimens described in the previous Section were numerically simulated in uniaxial compression. Typical stress-strain diagrams obtained for each type of geometry are given in Figure 3. Full post-peak behaviour was difficult to obtain even with advanced solution procedures and it was decided to concentrate in the peak strength, which is the most relevant issue of the present contribution. The behaviour observed shows that increasing distortion of the particles leads to decreasing brittleness. Moreover, a relation between brittleness and mesh refinement seems to be also present. In fact, specimens with a refinement level $n$ show a more brittle behaviour, characterized by sudden load drops, than specimens with refinement levels $2 n$ and $4 n$. However, it is noted that there is not much difference in the response beyond a level of refinement of $2 n$.

Table III illustrates the values for the compressive strength of the specimens $f_{c}$, according to the mesh distortion and level of refinement. It is noted that there is increasing variability of the strength values with increasing distortion and size of the particles. The variation obtained (it is stressed that a different mesh was generated for each analysis) fairly reproduces experimental variability of results. It is further noted that the strength values show a slight decreasing trend with increasing distortion, especially for lower levels of mesh refinement. Nevertheless, the average values for $2 n$ and $4 n$ can be considered as mesh size and mesh distortion independent for practical 
purposes. For this reason, relations between structural and particle sizes lower than seven to ten should be avoided.

take in Figure 3 and Table III

Figure 4 illustrates typical compressive crack propagation under increasing load. Three loading stages have been considered: $80 \%$ of the peak load, peak load and ultimate load. Well-known phenomena such as crack bridging and branching can be observed. Typical failure patterns obtained for the different specimens are depicted in Figure 5. It is clear that under certain combinations of particles distortion and mesh refinement, the failure pattern becomes biased by the mesh configuration. For instance, for $D F=0$ and $M R=4 n$, the crack pattern denotes a clear diagonal tendency while, for example, for $D F=0.6$ and $M R=4 n$, the crack pattern resembles experienced compression crack patterns with predominant vertical cracks. Thus, mesh configuration has a larger influence in the crack pattern of meshes with low distortion factors and high refinement levels. Nevertheless, the value of the failure load is not affected by the mesh preferential orientation.

take in Figure 4 and Figure 5

An assessment of the contribution of the interfaces tensile and shear parameters to the compressive strength of the specimens was also performed. To achieve this purpose, compression simulations assuming different values for the tensile parameters (strength and fracture energy) were considered firstly while the model shear parameters were kept constant, see Table IV. The same approach was repeated for the shear parameters and 
the results obtained are given in Table V. As expected, a decreasing trend of the compressive strength with decreasing values of the tensile and shear parameters was found, even if the simulation reduces the variation in the input significantly. However, the influence of the tensile parameters is smaller than the influence of the shear parameters. Such results seem to indicate that the compressive failure of the model in discussion is mainly governed by the parameters describing the shear behaviour.

take in Table IV and Table V

\section{Tensile uniaxial behaviour}

Figure 6 illustrates typical stress-strain diagrams obtained in uniaxial tensile simulations. Three types of tensile response can be clearly distinguished regardless of the particle size and mesh distortion. Each type of response is associated with a different failure pattern and, for each one, the specimen mode I fracture energy can range from a value similar to the mode I fracture energy given to the interface elements up to a very large value due to a residual plateau. Such residual plateau develops when diagonal cracks appear, originating friction between the particles due to the imposed boundary (symmetry) conditions. This is clearly a problem of the boundary conditions and not of the model approach.

\section{take in Figure 6}

The values obtained for the specimens tensile strength, according to the level of mesh refinement and the distortion factor, are given in Table VI. It is noted that the 
values found for the tensile strength found are in the range of $\pm 10 \%$ of the unitary value used as input for the tensile strength at meso-level. This is not only due the statistical simulation of disorder but also to the tortuous crack propagation, confirming the discussion addressed previously between macro and meso-properties. Slightly decreasing values for the tensile strength were found for increasing values of the distortion factor. However, the average values can be considered as mesh size and mesh distortion independent for practical purposes. Moreover, it is noted that increasing mesh refinement is accompanied by decreasing variability of the strength values and rather low values for the coefficient of variation are obtained for $M R=4 n$. Please note that the specimen size is always kept constant and only the size of the particles is reduced.

take in Table VI

Figure 7 illustrates typical tensile crack propagation under increasing loading. Again, three loading stages have been considered: $80 \%$ of the peak load, peak load and ultimate load. Initially, several cracks start developing but at some point localization of deformation occur in one crack while, in the others, unloading occurs. Figure 8 depicts typical failure patterns obtained for different refinement and distortion levels. Rather irregular failure patterns were obtained despite the particle size and mesh distortion, influencing the model response as shown above in Figure 6.

take in Figure 7 and Figure 8

\section{Size effect}


The effect of size is an important issue when estimating the strength or stressstrain relationship of quasibrittle materials. In the early 1980's, it became clear that size effect of such materials is mainly related with the release of the structure stored energy into the front of the propagating fracture or cracking zone and can not be explained solely by Weibull-type statistics of random micro-defects, see (Bazant and Planas, 1998) and (Kim and Yi, 2002) for a comprehensive reviews. In fact, the larger the structure, the greater is the volume from which the energy is released and since the fracture front dissipates the same amount of energy, regardless of the structure size, in a larger structure the failure load must be lower. Although size effect has been widely studied for tensile failure, cracking localization is also present under compressive loading and, thus, also compressed elements show size effect, e.g. (Van Mier, 1997). It is now well known that compressive strength and post-peak ductility tend to increase with decreasing size of the structural element.

In the field of concrete, models where the material structure is represented have been proved to be of great interest in understanding size effect phenomenon. In such simulations, the model parameters are set to a level below the level of observation (macro-level) and do not depend on size. Insight on this type of approach can be found in (Vonk, 1993) and (Van Vliet, 2000).

The ability of the proposed micro-model to describe the influence of the specimen size has been assessed by simulations on square specimens with $100 \times 100,50 \times 50$ and $10 \times 10 \mathrm{~mm}^{2}$. In addition, the influence of the shape of the specimen has been investigated by considering rectangular specimens with different height over width ratios $\left(10 \times 30 \mathrm{~mm}^{2}\right.$ and $\left.30 \times 10 \mathrm{~mm}^{2}\right)$. A distortion factor $D F=0.3$ and a mesh refinement $M R=2 n$ have been considered. In the case of square specimens, the mesh configuration and the material properties were kept constant, being the specimens only scaled. In this 
way, the results can be directly compared without the effect of randomness. In the case of the rectangular specimens, the same procedure could not be applied and three simulations were carried out for each shape considering the same average parameters adopted in the square specimens simulations.

From the stress-strain diagrams illustrated in Figure 9a it can be observed that the size of the specimens has a remarkable influence in the response of the model. In fact, size dependency is one of the advantages of particle-type models when compared to softening continuum models, see e.g. (Cusatis et al., 2003). Moreover, it is noted that the shape of the elements has a minor influence on the strength but an increase of brittleness was found for higher height over width ratios, see Figure 9b.

\section{take in Figure 9}

The size dependent responses exhibited by the model can be explained based on the following energy balance

$$
\int_{V} E d v=\int_{S} G_{f} d s
$$

where the first term is the volume integral of the maximum specific energy $E$ (by volume) stored in the specimen and the second term is the integral of the total energy released in the fracture process. $G_{f}$ is, then, the fracture energy given to the interfaces in the model. Moreover, specimens with equal strengths must store the same specific energy $E$. Considering equal shape 2D elements only differing by a scale factor, it is reasonable to assume that the crack patterns would resemble and that the number of cracks would be similar. In this way, the dissipation zone is increasing proportionally to the height of the specimen and, by energy balance, also is the stored energy. However, 
for the specimens to have the same strength, the maximum stored energy should be increasing proportionally to the area of the element. If the fracture energy given to the interface elements is modified to account for these aspects, see Equation (2), size independent responses are obtained.

$$
G_{f, 1}=G_{f, 2} \frac{b_{1}}{b_{2}}
$$

In the above, $b$ is the width of the specimens and the subscript stands for the different size specimens under consideration. Figure 12 illustrates the stress-strain diagrams obtained regarding the $100 \times 100 \mathrm{~mm}^{2}$ specimen as reference and by adapting the fracture energy (mode I and mode II) of the $50 \times 50 \mathrm{~mm}^{2}$ and $10 \times 10 \mathrm{~mm}^{2}$ specimens according to Equation 2. It can be observed that the response becomes totally independent from the specimen size. When there is only an increase in the height or width of the specimen, it was shown that the strength value predicted by the particle model is almost not affected, see Figure 9b. This can be explained by the fact that the increase of the stored energy is proportional to the increase of the dissipation zone. In fact, in the case of an increase in height, the cracks length can be assumed to increase roughly as much as the specimen height while in the case of an increase in width, the number of cracks can be considered to increase proportionally

take in Figure 12

\section{MODELLING MASONRY}


In the previous sections the proposed particle model has been introduced and insight on the model behaviour has been provided. In this Section, the ability of the model to reproduce the behaviour of running-bond masonry prisms under uniaxial compression is assessed by means of a comparison with experimental results and with numerical results using a non-linear continuum finite element model.

\section{Brief description of adopted experimental results}

(Binda et al., 1988) carried out deformation controlled tests on running bond masonry prisms with dimensions of $600 \times 500 \times 250 \mathrm{~mm}^{3}$, built up with nine courses of $250 \times 120 \times 55 \mathrm{~mm}^{3}$ solid soft mud bricks and $10 \mathrm{~mm}$ thick mortar joints. Three different types of mortar, denoted as $M 1, M 2$ and $M 3$, have been considered and testing aimed at the evaluation of the compressive properties of the prisms. For each type of mortar, a total of three prisms were tested.

The tests were carried out in a uniaxial testing machine MTS $^{\circledR} 311.01 .00$, with non-rotating steel plates and a maximum capacity of $2500 \mathrm{kN}$. The applied load was measured by a load cell located between the upper plate and the testing machine, while displacements up to the peak load were measured with a removable strain gauge, see Figure 10. In addition, the average vertical displacement of each prism was also recorded with the machine in-built displacement transducer, permitting to capture the complete stress-strain diagram, including the softening regime. In this study, the prisms vertical strains and elastic moduli were calculated from the transducer measured displacements. Teflon sheets were placed between the prisms and the loading plates in order to minimize restraining frictional stresses. 
The characteristics of the masonry components in terms of compressive strength $f_{c}$, flexural tensile strength $f_{f}$, elastic modulus $E$ and coefficient of Poisson $v$ are given in Table VII. The results obtained for the prisms are given in Table VIII. Prisms $P 1, P 2$ and $P 3$ were built with mortars $M 1, M 2$ and $M 3$ of increasing strength, respectively. The experimental failure patterns found were rather similar despite the type of mortar used, (Frigerio and Frigerio, 1985). Figure 11 depicts the typical failure pattern.

take in Figure 10

take in Table VII and Table VIII

take in Figure 11

\section{Description of the continuum model}

The simulations were carried out resorting to a basic cell, i.e., a periodic pattern associated to a frame of reference, see Figure 13, in which units and mortar were represented by a structured continuum finite element mesh. However, to reduce computational effort only a quarter of the basic cell was modelled assuming symmetry conditions for the in-plane boundaries, see Figure 14. The dimensions of the components are equal to the ones used in the experiments.

take in Figure 13 and Figure 14

Three different plane approaches can be considered taking into account the out-ofplane boundaries, namely: (a) plane-stress $P S$, (b) plane-strain $P E$ and (c) an intermediate state, here named enhanced-plane-strain EPE. This last approach consists 
in modelling a thin out-of-plane masonry layer with 3D elements, imposing equal displacements in the two faces of the layer. Full 3D analyses with refined meshes and softening behaviour are unwieldy, and were not considered. Moreover, recent research indicated that enhanced-plane-stress analysis provides very similar results, see (Berto et al., 2005). EPE response is always between the extreme responses obtained with $P S$ and $P E$. For this reason, $E P E$ is accepted as the reference solution for the continuum simulations and only its results are considered in this paper. A complete description of the continuum simulations can be found in (Pina-Henriques and Lourenço, 2003).

Modelling of the cell in EPE was carried out using approximately 900 20-noded brick elements with 6650 nodes, totalling 13300 degrees of freedom (note that the tying adopted for the out-of-plane degrees of freedom mean that, basically, a 2D model is used). $3 \times 3 \times 3$ Gauss integration was used. The material behaviour was described using a composite model including a traditional smeared crack model in tension, specified as a combination of tension cut-off (two orthogonal cracks), tension softening and shear retention, see (Rots, 1988), and a Drucker-Prager plasticity model in compression, see also (DIANA, 2003). The inelastic behaviour exhibits a parabolic hardening/softening diagram in compression and an exponential-type softening diagram in tension. The material behaves elastically up to one-third of the compressive strength and up to the tensile strength.

\section{Description of the particle model}

The particle model simulations were carried out employing the same basic cell used for the continuum model, see Figure 13. The particle model is composed by approximately 
13000 linear triangular continuum elements, 6000 linear line interface elements and 15000 nodes, see Figure 15. Macro homogeneous symmetry conditions and a distortion factor equal to 0.3 have been assumed. It is emphasised that the basic cell approach is only approximate of the real geometry of the specimens and that the obtained numerical response is phenomenological, which means that a comparison in terms of experimental and numerical failure patterns is not possible. In particular, splitting cracks usually observed in prisms tested under compression, e.g. (Mann and Betzler, 1994), boundary effects of the specimen and non-symmetric failure modes are not captured by the numerical analysis. Nevertheless, most of these effects control mainly the post-peak response, which is not the key issue in the present contribution.

\section{take in Figure 15}

The material parameters were defined by comparing the experimental and numerical responses of units and mortar considered separately. Each material was modelled resorting to specimens with the same average particle size, mesh distortion and dimensions of the masonry components used in the composite model (basic cell).

Given the stochastic nature of the model, five simulations were performed for each masonry component assuming equal average values for the model material parameters. The parameters were obtained, whenever possible, from the described experimental tests but most of the inelastic parameters were unknown and had to be estimated. It is noted that the particles average elastic modulus $E$ is larger than the experimental value due to the contribution of the interfaces deformability, characterized by $k_{n}$ and $k_{s}$, to the overall deformability of the specimen. This correction is necessary despite the high dummy stiffnesses assumed. 
On the contrary, the values adopted for the interfaces tensile strength $f_{t}$ are slightly lower than the specimens experimental tensile strength, given the contribution of the interfaces shear strength due to the irregular fracture plane. Again, the cohesion $c$ was taken, in general, equal to $1.5 f_{t}$ (Lourenço, 1996). However, quite low experimental ratios between the compressive and tensile strengths were reported for the units and mortars considered here, with values ranging between four and eight. Due to this reason, cohesion values lower than $1.5 f_{t}$ had to be adopted for mortars $M 1$ and $M 2$.

The values for the friction coefficient $\tan \phi$ were adopted so that the numerical compressive strength showed a good agreement with the experimental strength. The values assumed for mode I fracture energy $G_{f I}$ have been based in recommendations supported in experimental evidence, see (CEB-FIP, 1993) and (Van der Pluijm, 1999). For mode II fracture energy $G_{f I I}$, a value equal to $0.5 c$ was assumed, with the exception of the very high strength mortar $M 3$, for which a lower value equal to $0.3 c$ was adopted.

The complete material parameters adopted are given in Table IX and, for such input, the response obtained is given in Table X. In addition, typical numerical stressstrain diagrams for both units and mortar specimens are illustrated in Figure 16.

take in Table IX, Table $X$ and Figure 16

\section{Numerical results and comparison with experimental data}


In order to reproduce correctly the elastic stiffness of the masonry prisms, the experimental elastic modulus of the mortar $E$ must be adjusted by inverse fitting. In fact, the mortar experimental stiffness leads to a clear overstiff response of the numerical specimens. This can be explained by the fact that the mechanical properties of mortar inside the composite are different from mortar specimens cast separately. This is due to mortar laying and curing and represents a severe drawback of detailed micromodels. Table XI gives the adjusted mortar stiffness values $E^{*}$ used in the simulations.

\section{take in Table XI}

The numerical results obtained for the masonry prisms considering the mortar experimental Num_E and adjusted $N u m_{-} E^{*}$ stiffnesses are given in Table XII, where $f_{c}$ is the compressive strength and $\varepsilon_{p}$ is the peak strain. In addition, the prisms experimental results are shown for a better comparison. It is noted, however, that the reference solution for the numerical simulations is the solution provided by Num_E* Figure 17 depicts the experimental and numerical stress-strain diagrams.

\section{take in Table XII and Figure 17}

From the given results, it is clear that the experimental collapse load is overestimated by the particle and continuum models, and that the predicted strength is affected by the mortar stiffness, especially in the case of the particle model. However, a much better agreement with the experimental strength and peak strain has been achieved with the particle model, when compared to the continuum model. In fact, the numerical over experimental strength ratios ranged between 165 to $170 \%$ in the case of the 
continuum model while in the case of the particle model, strength ratios ranging between 120 and $140 \%$ were found. The results obtained also show that the peak strain values are well reproduced by the particle model but large overestimations are obtained with the continuum model. In fact, for this last model, experimental over numerical peak strain ratios ranging between 190 and 510\% were found.

Failure patterns are an important feature when assessing numerical models. The (incremental) deformed meshes near failure are depicted in Figure 18 to Figure 20 for the continuum model and in Figure 21 for the particle model. In the case of the continuum model, the contour of the minimum principal plastic strains is also given for a better interpretation of the mechanisms governing failure. It is noted that despite the fact that only a quarter of the basic cell has been modelled, the results are shown in the entire basic cell to obtain more legible figures.

take in Figure 18 to Figure 21

The numerical failure patterns obtained are similar for both continuum and particle models. Even if the proposed particle model approach is phenomenological, the failure patterns resemble well typical compression experimental patterns observed in the face of masonry specimens. In the case of prism $P 1$, failure occurs mainly due to the development of vertical cracks in the centre of the units and along the head-joints, being the mortar in the bed-joints severely damaged. Prism $P 2$ fails due to diffuse damage developing in units and mortar in a rather uniform manner. In the case of prism $P 3$, diffuse damage is also present but localized crushing of the units can be clearly observed at one-half and one-sixth of the units length. 


\section{CONCLUSIONS}

The analysis of masonry assemblages using detailed modelling strategies is a challenging task. A particle model consisting in a phenomenological discontinuum approach has been proposed to represent the microstructure of masonry components, attempting to adequately reproduce the experimental behaviour of masonry under compression. The model is discussed in detail, including proposals for selection of numerical data, sensitivity studies, fracture processes and failure mechanisms, and size effect studies. Finally, the particle model is compared with experimental results on masonry wallets under uniaxial compression and with numerical simulations using a continuum finite element model.

It is possible to conclude that: (a) discontinuum models show clear advantages when compared to standard continuum models, based on plasticity and cracking, in predicting the compressive strength and peak strain of masonry prisms from the properties of the constituents; (b) compressive and tensile strength values provided by the particle model can be considered as particle size and particle distortion independent for practical purposes; (c) relations between structural and particle sizes lower than seven to ten should be avoided in simulations; (d) size dependent responses have been obtained with the proposed model; and (e) shear parameters rather than tensile parameters play a major role at the micro-level and greatly influence the overall response of compressed masonry, as also confirmed by Vonk (1993).

Suggestions for further work include validation of the proposed model for the full 2D failure envelop under biaxial loading, develop more robust solution strategies to allow tracing the softening response of the masonry-composite simulations using the proposed model, extension of the proposed particle model to 3D configurations and 
seek for other models developed in discontinuum frameworks in order to provide reliable estimations of masonry compressive strength. Finally, also the ability of nonstandard continuum models, such as the microplane model, Adicionar referência Bazant et al, to simulate the compression failure of masonry based on the geometry and properties of the constituents should be evaluated.

\section{ACKNOWLEDGEMENTS}

The financial support by the Portuguese Foundation for Science and Technology (FCT) under grant SFRH/BD/5002/2001 awarded to J. Pina-Henriques is gratefully acknowledged.

\section{REFERENCES}

ACI (2004), “Commentary on specification for masonry structures”, ACI 530.102, Manual of Concrete Practice, Detroit, USA.

Bazant, Z.P. and Planas, J. (1998), Fracture and Size Effect in Concrete and other Quasibrittle Materials, CRC Press, Florida, USA.

Berto, L., Saetta, A., Scotta, R. and Vitaliani, R. (2005), “Failure mechanism of masonry prism loaded in axial compression: computational aspects”, Materials and Structures, RILEM, Vol 38, No 276, pp. 249-256.

Binda, L., Fontana, A. and Frigerio, G. (1988), "Mechanical behaviour of brick masonries derived from unit and mortar characteristics”, Proc $8^{\text {th }}$ International Brick/Block Masonry Conference, Dublin, Ireland, Vol 1, pp. 205-216. 
Bolander, J.E., Hong, G.S. and Yoshitake, K. (2000), “Structural concrete analysis using rigid-body-spring networks”, Computer-Aided Civil and Infrastructure Engineering, Vol. 15, pp. 120-133.

Brencich, A. and Gambarotta, L. (2005), “Mechanical response of solid clay brickwork under eccentric loading. Part I: unreinforced masonry”, Materials and Structures, RILEM, Vol 38, No 276, pp. 257-266.

Carol, I., López, C.M. and Roa, O. (2001), “Micromechanical analysis of quasibrittle materials using fracture-based interface elements”, International Journal of. Numerical Methods in Engineering, Vol 52, pp. 193-215.

CEB-FIP (1993), CEB-FIP Model Code 1990, Bulletin D’Information No 213/214, Comite Euro-International du Beton, T Telford, London, UK.

CEN (1998), Methods of Test for Masonry: Determination of Compressive Strength, EN 1052-1:1998, Brussels, Belgium.

CEN (2003), Eurocode 6: Design of Masonry Structures, prEN 1996-1-1:2002, Brussels, Belgium.

Cundall, P.A. (1971), “A computer model for simulating progressive, large scale movements in blocky rock systems”, Proc Symposium International Society Rock Mechanics, Nancy, France, Vol 1 No II-8, pp. 129-136.

Cusatis, G., Bazant, Z.P. and Cedolin, L. (2003), "Confinement-shear lattice model for concrete damage in tension and compression”, Journal of Engineering Mechanics, ASCE, Vol 129, No 12, pp. 1439-1458.

DIANA (2003), “DIANA Finite Element Code, Version 8.1”, TNO Building and Construction Research, The Netherlands. 
Frigerio, G. and Frigerio, P. (1985), Influence of the Components and Surrounding Environment in the Mechanical Behaviour of Brick Masonry (in Italian), Graduation thesis, Politecnico di Milano, Milan, Italy.

Gens, A., Carol, I., and Alonso, E. (1988), “An interface element formulation for the analysis of soil-reinforcement interaction”, Computers and Geotechnics, Vol 7, pp. 133-151.

Ingraffea, A.R. and Saouma, V.E. (1985), “Numerical modelling of discrete crack propagation in reinforced and plain concrete”, Fracture Mechanics of Concrete, eds. Sih, G. and Tomasso, A. Di, Martinus Nijhoff Publishers, Dordrecht, The Netherlands, pp. 171-225.

Jing, L. (2003), “A review of techniques, advances and outstanding issues in numerical modelling for rock mechanics and rock engineering”, International Journal of Rock Mechanics \& Mining Sciences, Vol 40, pp. 283-353.

Kim, J.K. and Yi, S.T. (2002), “Application of size effect to compressive strength of concrete members”, Sadhana, Vol 27, No 4, pp. 467-484.

Lemos, J.V. (2001), "Modelling the behaviour of a stone masonry arch structure under cyclic loads”, Proc $5^{\text {th }}$ International Symposium on Computer Methods in Structural Masonry, Rome, Italy, pp. 101-108.

Lotfi, H.R. and Shing, P.B. (1994), "Interface model applied to fracture of masonry structures”, Journal of Structural Engineering, ASCE, Vol 120, No 1, pp. 63-80.

Lorig, L.J. and Cundall, P.A. (1987), “Modelling of reinforced concrete using the distinct element method”, Proc SEM/RILEM International Conference on Fracture of Concrete and Rock, Houston, USA, pp. 459-471. 
Lourenço, P.B. (1996), A User/Programmer Guide for the Micro-modelling of Masonry Structures, Report 03.21.1.31.35, Delft University of Technology, Delft, The Netherlands. Available from http://www.civil.uminho.pt/masonry.

Lourenço, P.B. and Rots, J.G. (1997), “A multi-surface interface model for the analysis of masonry structures”, Journal of Engineering Mechanics, ASCE, Vol 123 No 7, pp. 660-668.

Mann, W. and Betzler, M. (1994), "Investigations on the effect of different forms of test samples to test the compressive strength of masonry”, Proc $10^{\text {th }}$ International. Brick and Block Masonry Conference, Calgary, Canada, pp. 1305-1313.

Pina-Henriques, J. and Lourenço, P.B. (2003), “Testing and modelling of masonry creep and damage in uniaxial compression”, Proc International Conference on Structural Studies, Repairs and Maintenance of Heritage Architecture, Halkidiki, Greece, pp. 151-160.

QHULL (2001), “QHULL, Version 3.1”, Barber, C.B. and Huhdanpaa, H., University of Minnesota, Minneapolis, USA.

Roman, H.R. and Gomes, I.R. (2004), “Numerical modelling of blockwork prisms tested in compression using the finite element method with interface behaviour”, Proc. $13^{\text {th }}$ International Brick/Block Masonry Conference, Amsterdam, The Netherlands, Vol 2, pp. 421-429.

Rots, J.G. (1988), Computational Modelling of Concrete Fracture, PhD thesis, Delft University of Technology, Delft, The Netherlands.

Rots, J.G. and Schellekens, J.C.J. (1990), "Interface elements in concrete mechanics”, Computer Aided Analysis and Design of Concrete Structures, eds. Bicanic, N. and Mang, H., Pineridge Press, Swansea, UK, pp. 909-918. 
Schellekens, J.C. (1992), Computational Strategies for Composite Structures, PhD thesis, Delft University of Technology, Delft, The Netherlands.

Schlangen, E. (1993), “Experimental and numerical analysis of fracture processes in concrete”, Heron, Vol 38 No 2, pp. 1-117.

Schubert, P. (1988), "The influence of mortar on the strength of masonry”, Proc. $8^{\text {th }}$ International Brick/Block Masonry Conference, London, UK, pp. 162-174.

Shi, G.H. (1988), Discontinuous Deformation Analysis - a New Numerical Model for the Statics and Dynamics of Block Systems, PhD thesis, University of California, Berkeley, USA.

Van der Pluijm, R. (1999), Out-of-plane Bending of Masonry: Behaviour and Strength, PhD thesis, Delft University of Technology, Delft, the Netherlands.

Van Mier, J.G.M., Schlangen, E. and Vervuurt, A. (1995), “Lattice type fracture models for concrete”, in Mühlhaus, H. (Ed.), Continuum Models for Materials with Microstructure, John Wiley \& Sons, New York, USA, pp. 341-377.

Van Mier, J.G.M. (1997), Fracture Processes of Concrete, CRC Press, Boca Raton, USA.

Van Vliet, M. (2000), Size Effect in Tensile Fracture of Concrete and Rock, PhD thesis, Delft University of Technology, Delft, The Netherlands.

Vonk, R.A. (1993), “A micromechanical investigation of softening of concrete loaded in compression”, Heron, Vol 38 No 3, pp. 1-94. 


\section{FIGURES}

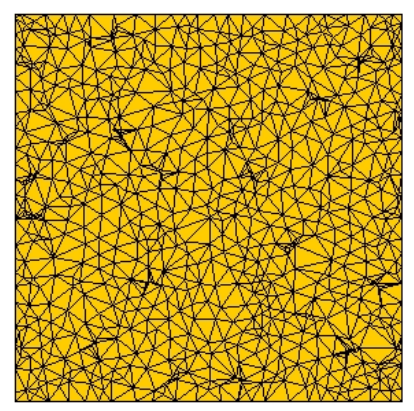

(a)

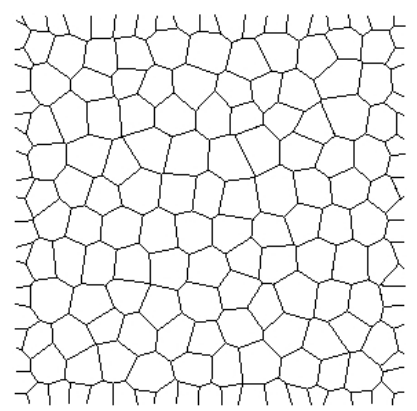

(b)

Figure 1 - Finite element mesh: (a) particles mesh and (b) interfaces mesh. 


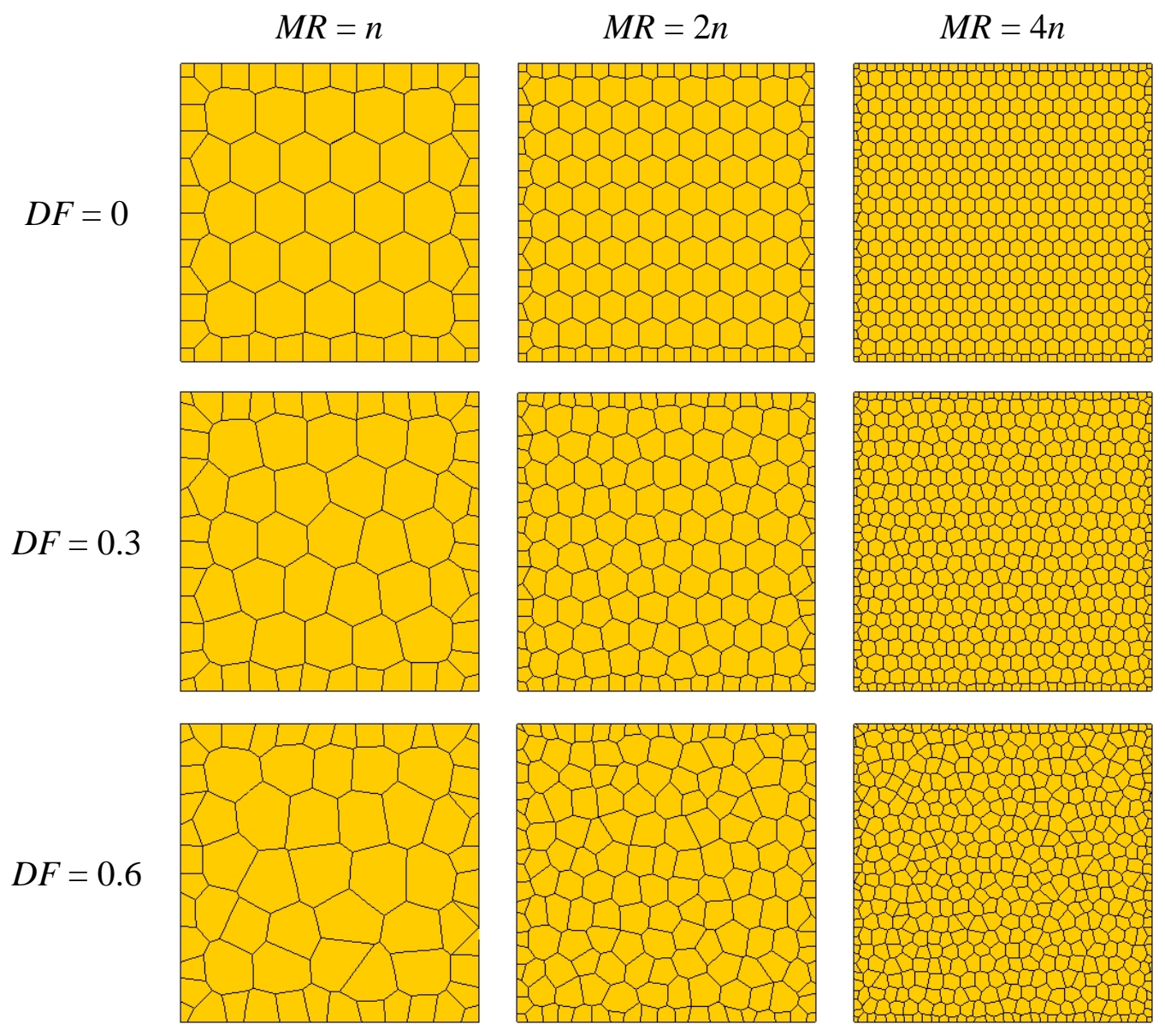

Figure 2 - Geometry of the $100 \times 100 \mathrm{~mm}^{2}$ specimens used in the simulations. Three distortion factors $D F$ and mesh refinement levels $M R$ were considered. 




(a)

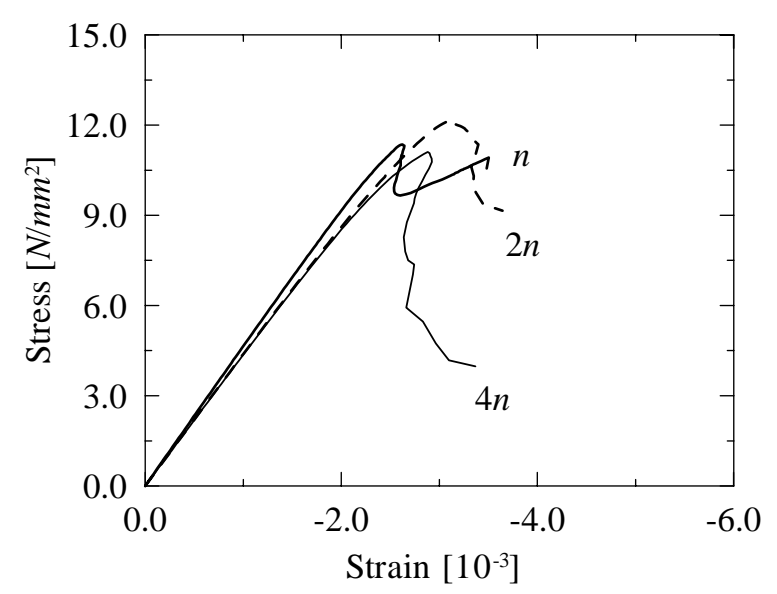

(b)

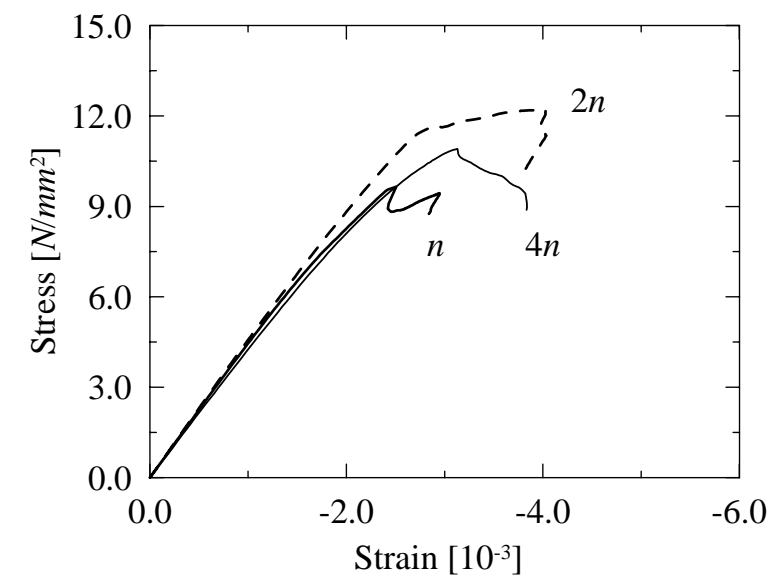

(c)

Figure 3 - Typical compressive stress-strain diagrams obtained for three different levels of mesh refinement ( $n, 2 n$ and $4 n)$ and three different distortion factors:

(a) $D F=0$, (b) $D F=0.3$ and (c) $D F=0.6$. 


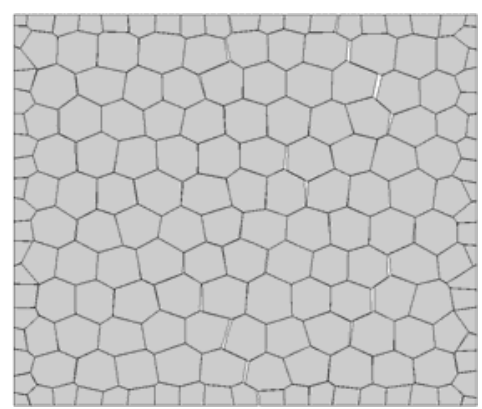

(a)

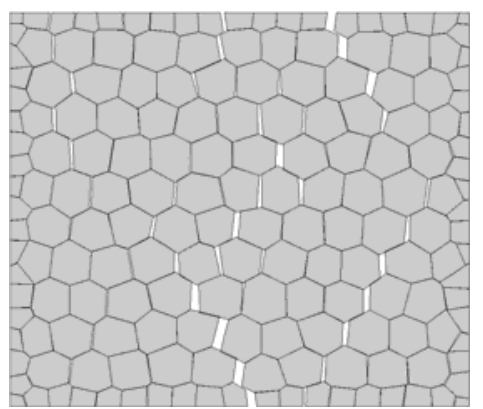

(b)

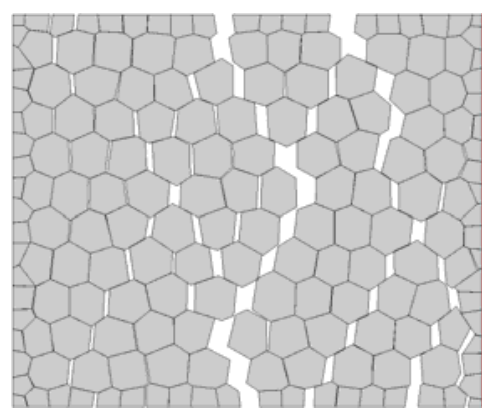

(c)

Figure 4 - Typical progressive compressive failure of a specimen. Deformed meshes at: (a) $80 \%$ of the peak load, (b) peak load and (c) ultimate load. 


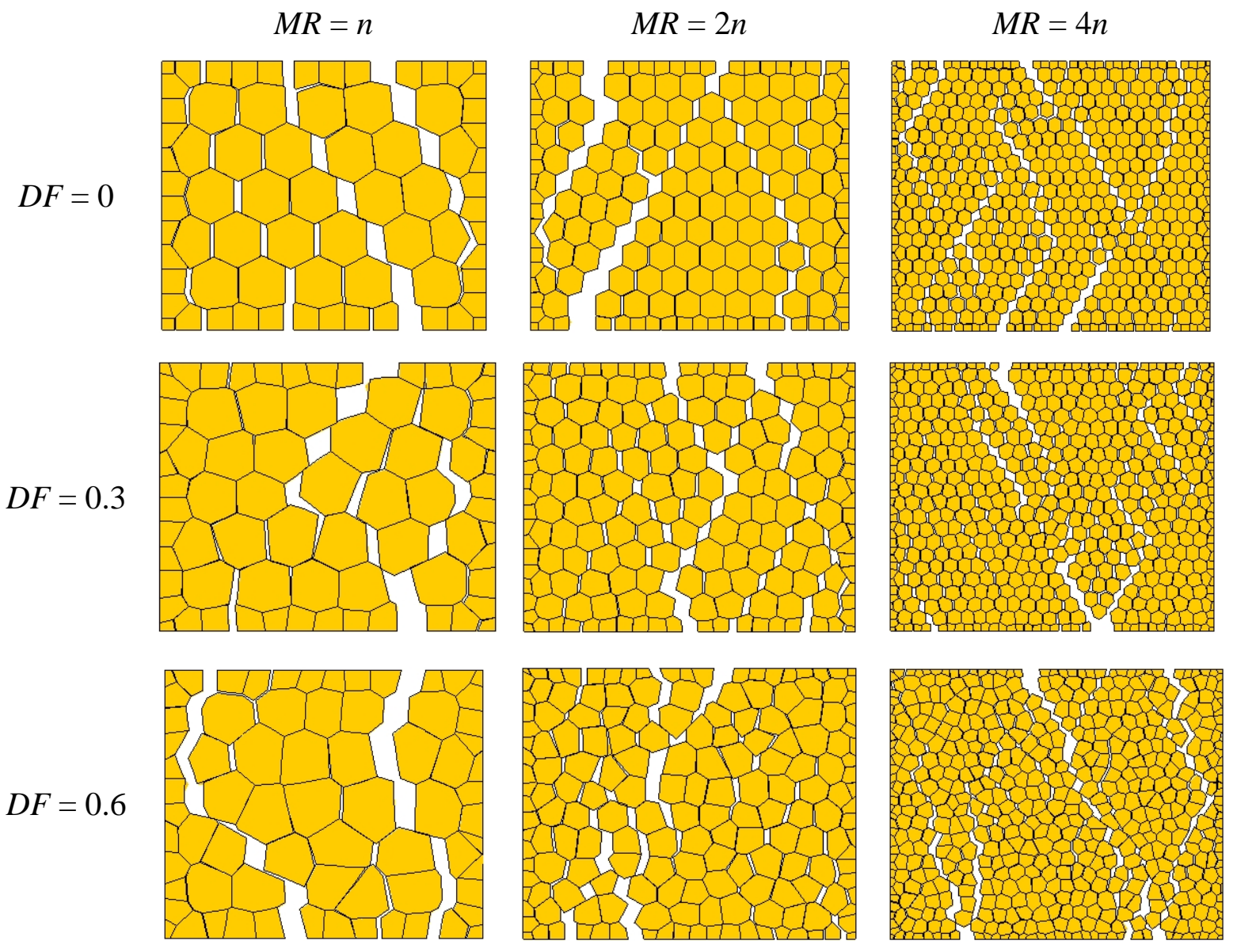

Figure 5 - Typical deformed meshes obtained from the compression simulations, using three distortion factors $D F$ and mesh refinement levels $M R$. 


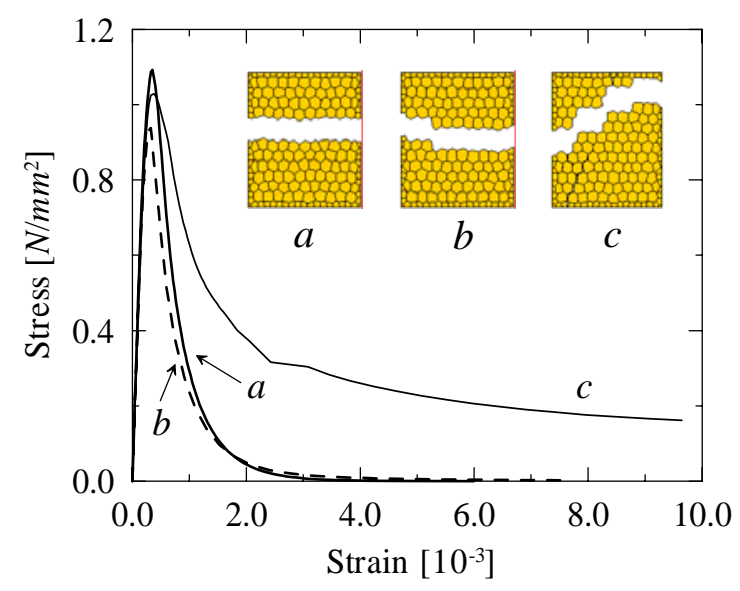

Figure 6 - Tensile stress-strain diagrams and failure patterns obtained for specimens with $M R=2 n$ and $D F=0.3$.

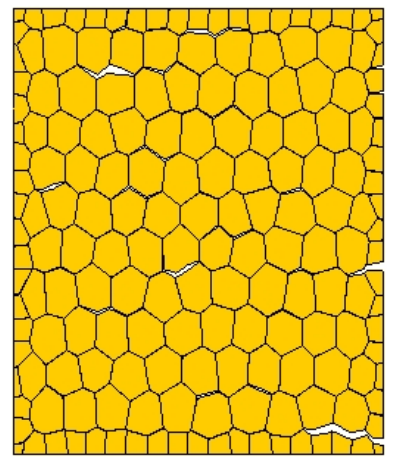

(a)

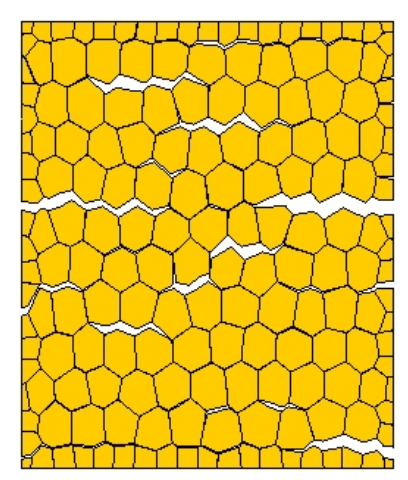

(b)
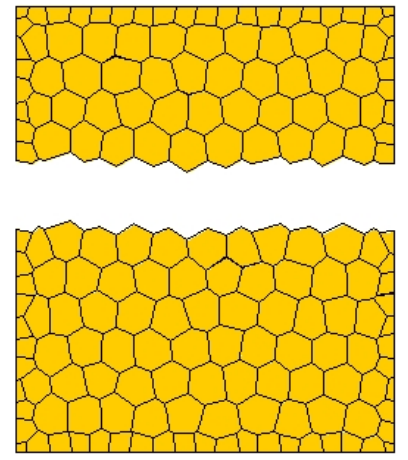

(c)

Figure 7 - Typical progressive tensile failure of a specimen. Deformed meshes at: (a) $80 \%$ of the peak load, (b) peak load and (c) ultimate load. 


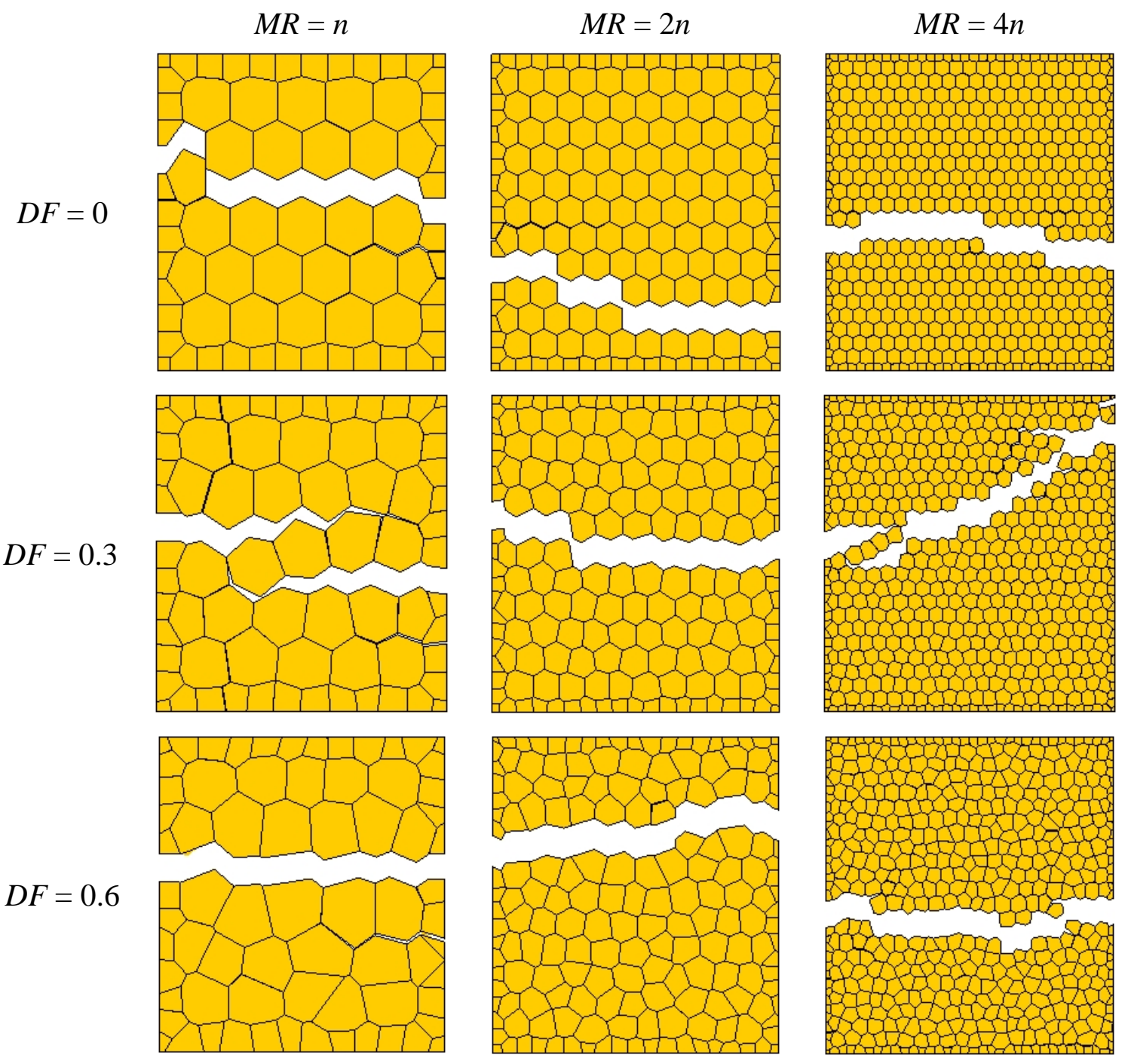

Figure 8 - Typical deformed meshes obtained from the tension simulations. Three distortion factors $D F$ and mesh refinement levels $M R$ were considered. 


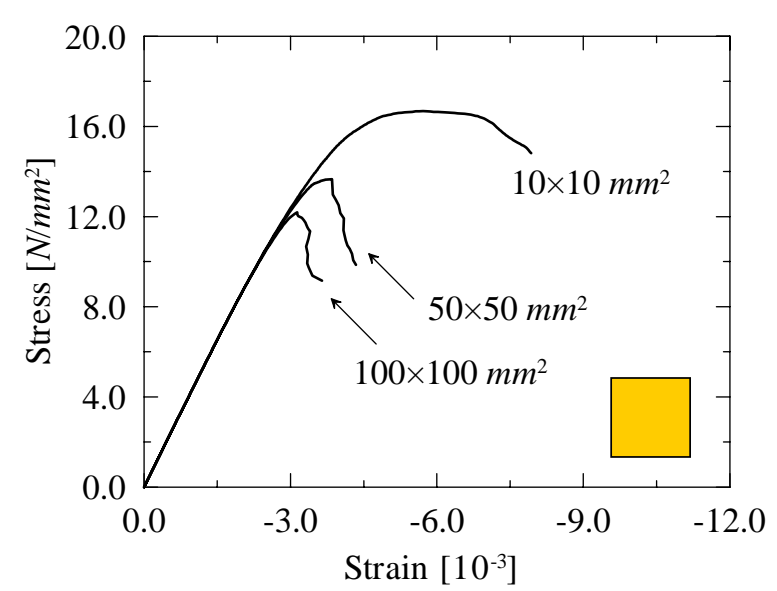

(a)

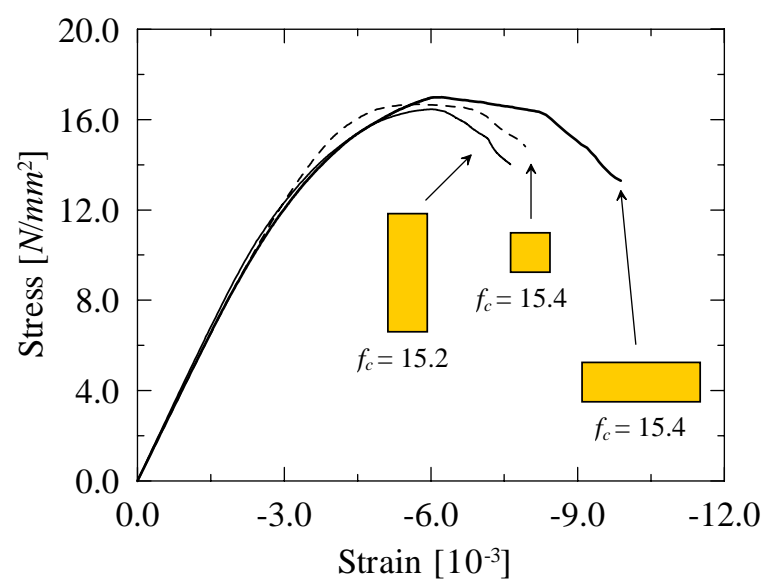

(b)

Figure 9 - Stress-strain diagrams obtained for specimens with: (a) different size and (b) different shape. In this last figure, typical diagrams and the average compressive strength values $f_{c}$ obtained from three different simulations are given for each shape $\left(10 \times 30,10 \times 10\right.$ and $\left.30 \times 10 \mathrm{~mm}^{2}\right)$. 

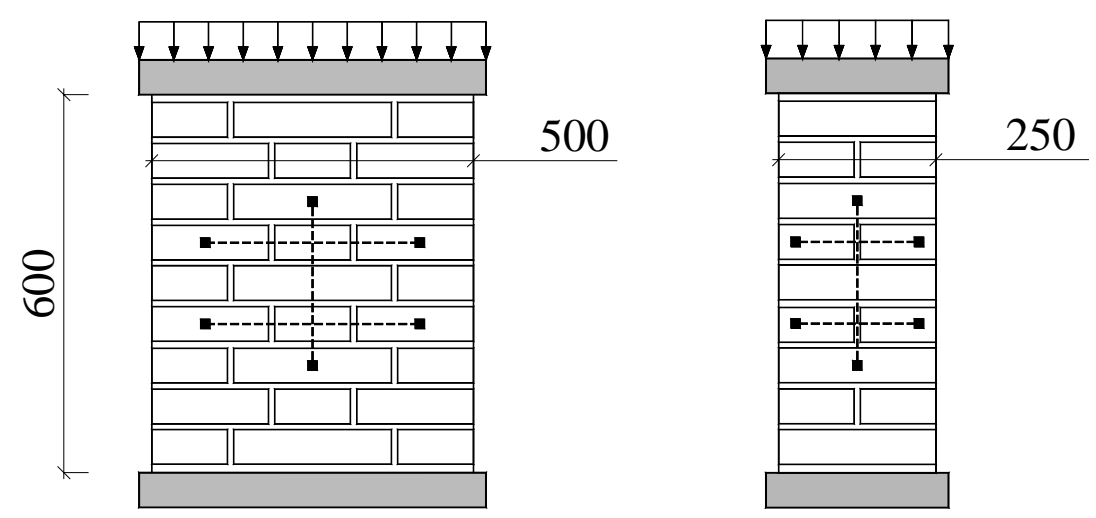

Figure 10 - Tested masonry wallets and location of strain gauge measurements, Binda et al. (1988). The dimensions are in $\mathrm{mm}$.
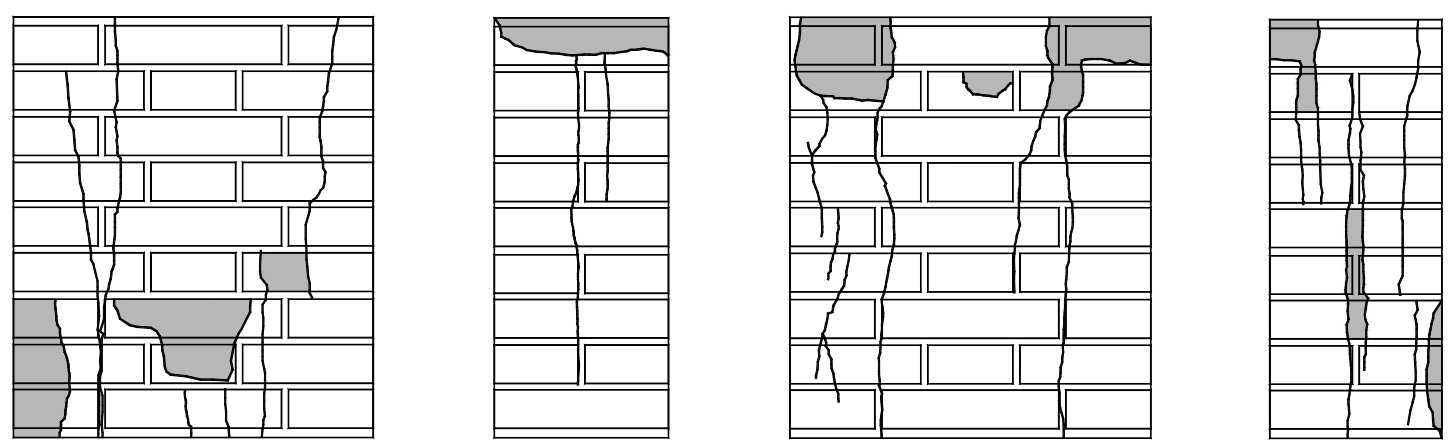

Figure 11 - Typical experimental failure patterns, Frigerio and Frigerio (1985). The shaded areas indicate spalling of material. 


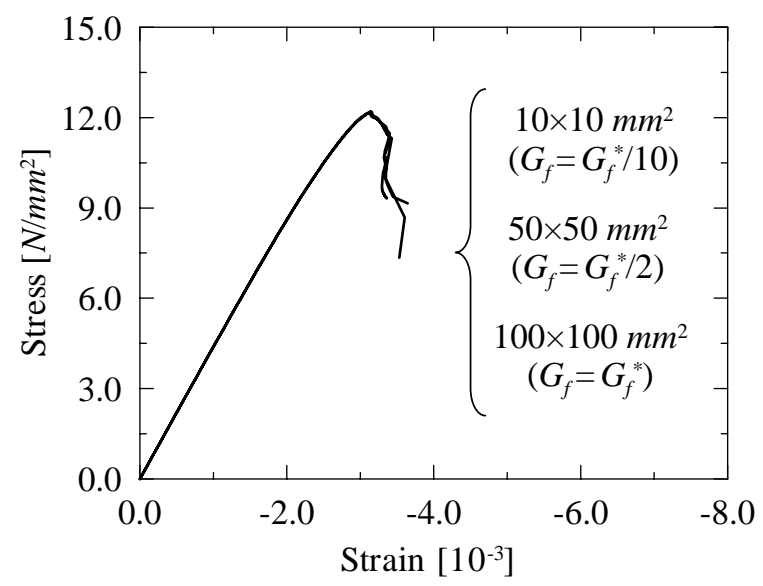

Figure 12 - Stress-strain diagrams obtained by adapting the fracture energy $G_{f}$ as a function of the initial value $G_{f}^{*}$ in order to obtain a size independent response.

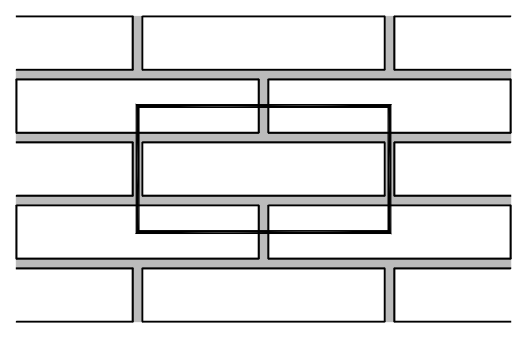

(a)

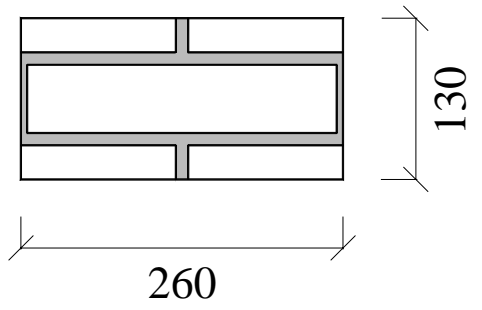

(b)

Figure 13 - Definition of basic cell: (a) running bond masonry and (b) geometry.

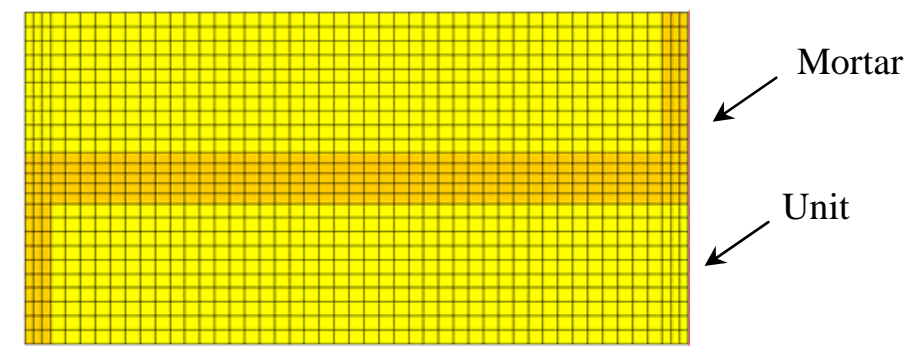

Figure 14 - Continuum model (a quarter of the basic cell, assuming symmetry conditions). 


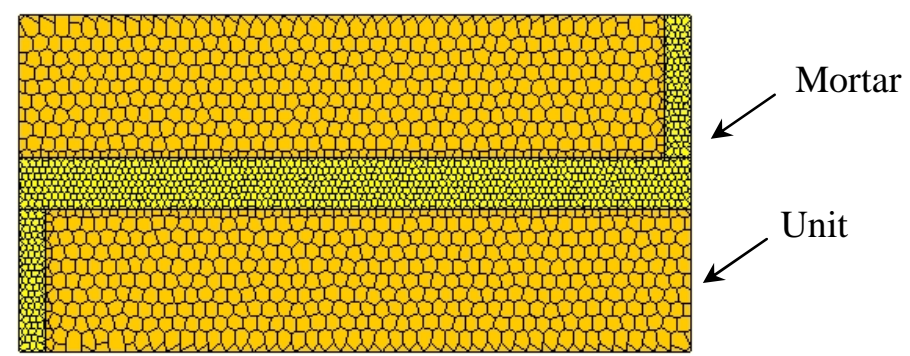

Figure 15 - Particle model (a quarter of the basic cell, assuming symmetry conditions).

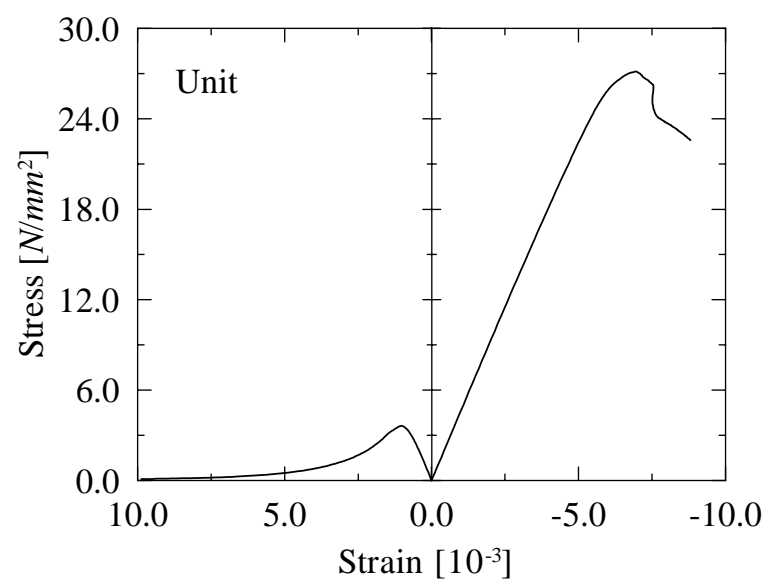

(a)

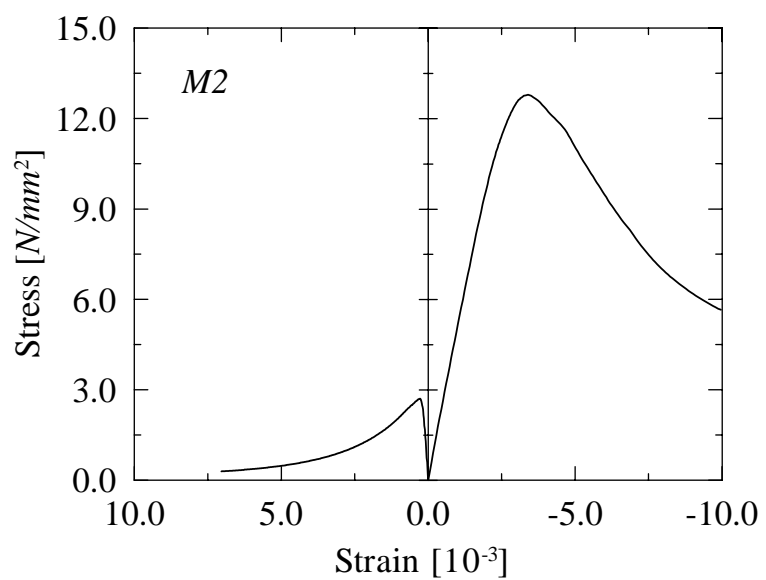

(c)

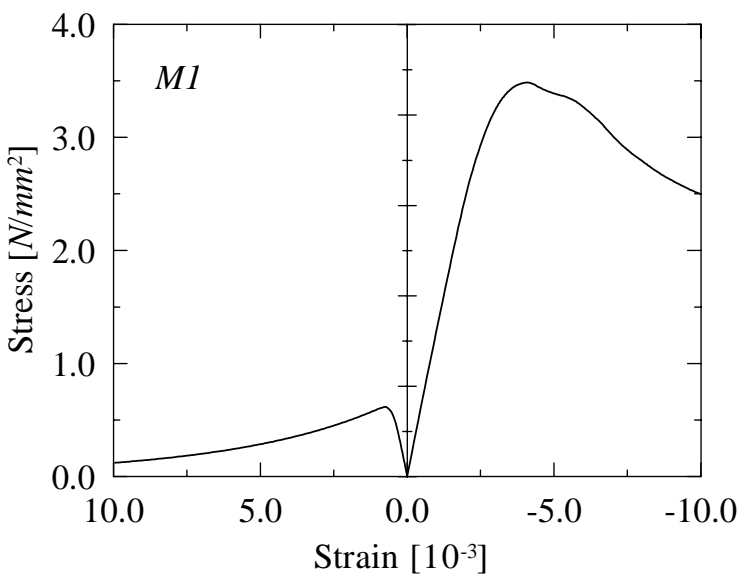

(b)

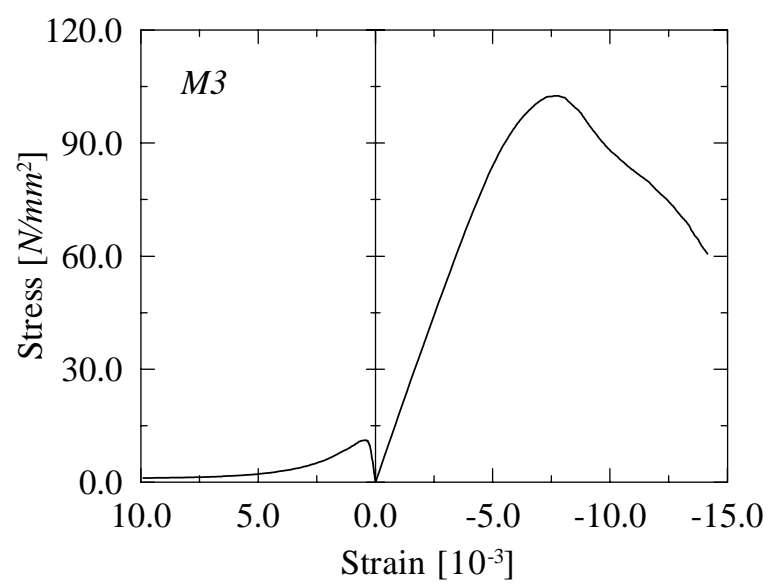

(d)

Figure 16 - Typical numerical stress-strain diagrams obtained for the masonry components:

(a) unit, (b) mortar M1, (c) mortar M2 and (d) mortar M3. 


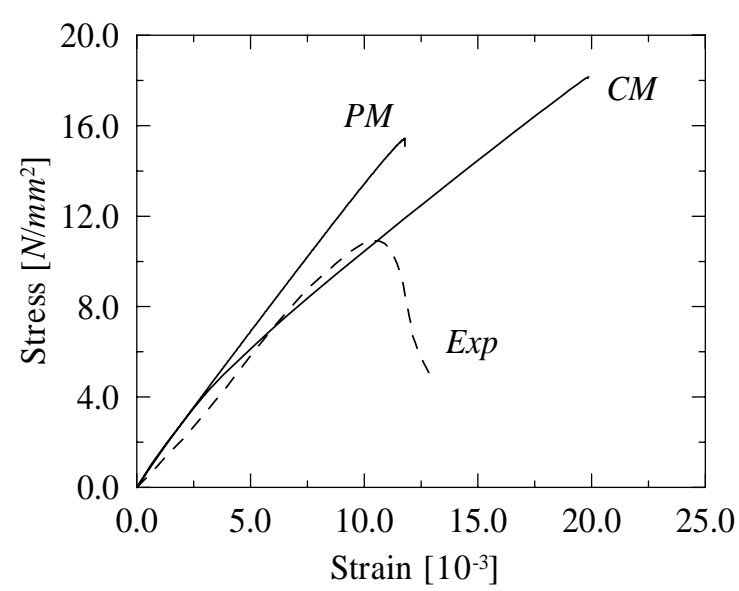

(a)

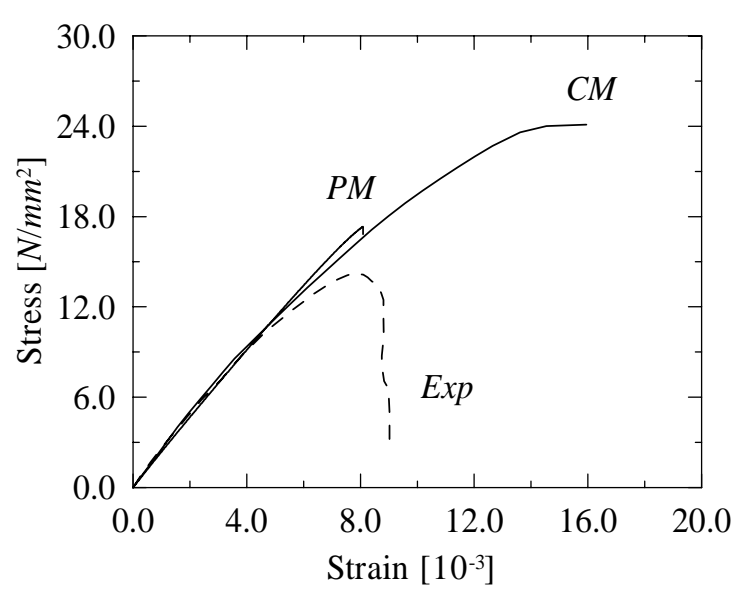

(b)

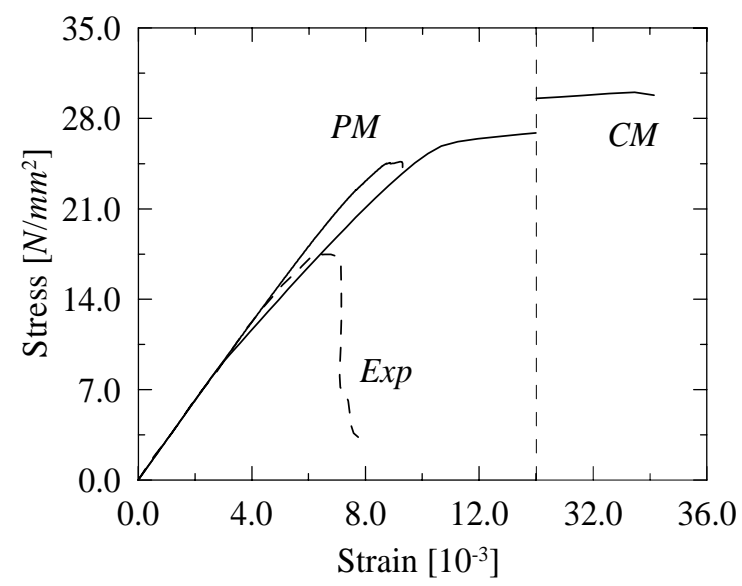

(c)

Figure 17 - Numerical and experimental stress-strain diagrams, using adjusted mortar stiffness values, for prism: (a) $P 1$, (b) $P 2$ and (c) $P 3$. In the diagrams, $P M$ stands for particle model, CM for continuum model, and Exp for experimental data. 


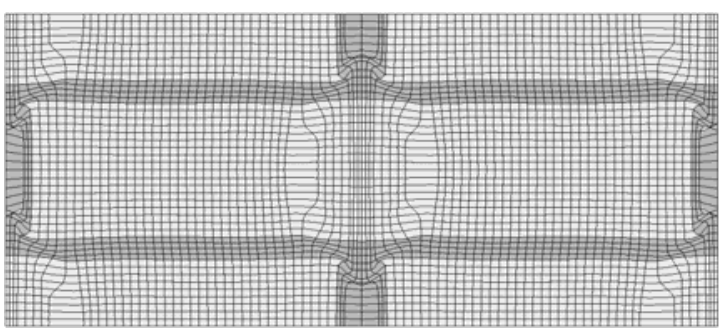

(a)

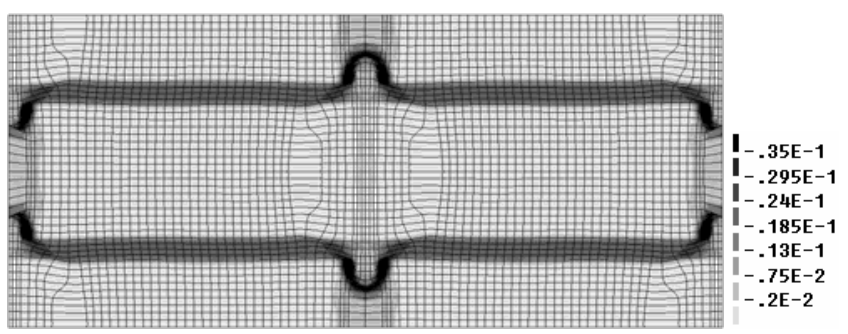

(b)

Figure 18 - Results obtained at failure for prism P1 using the continuum model: (a) deformed (incremental) mesh and (b) minimum principal plastic strains.

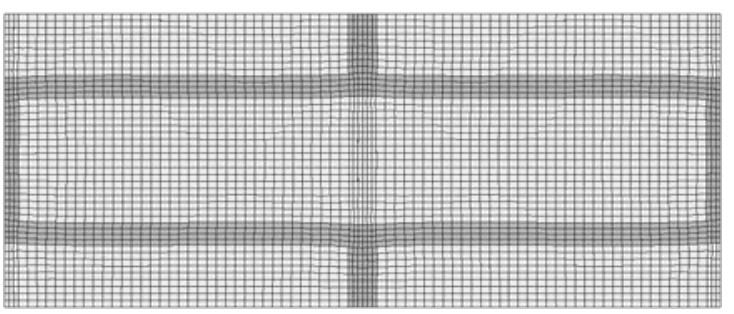

(a)

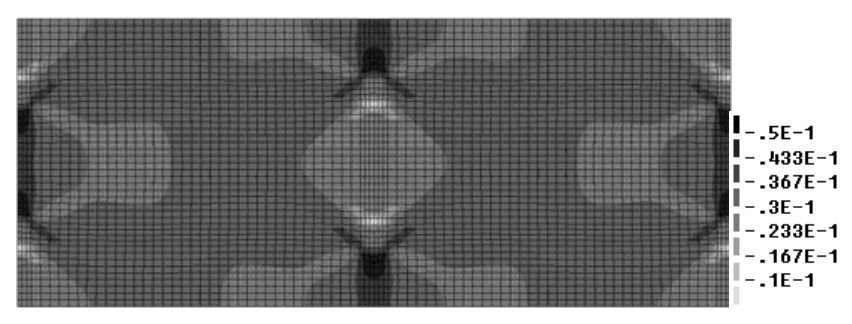

(b)

Figure 19 - Results obtained at failure for prism P2 using the continuum model: (a) deformed (incremental) mesh and (b) minimum principal plastic strains.

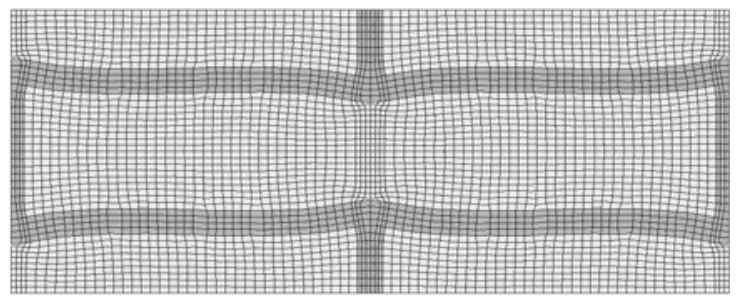

(a)

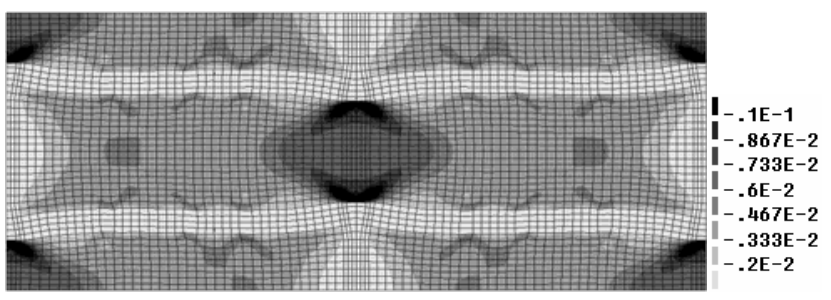

(b)

Figure 20 - Results obtained at failure for prism P3 using the continuum model: (a) deformed (incremental) mesh and (b) minimum principal plastic strains. 


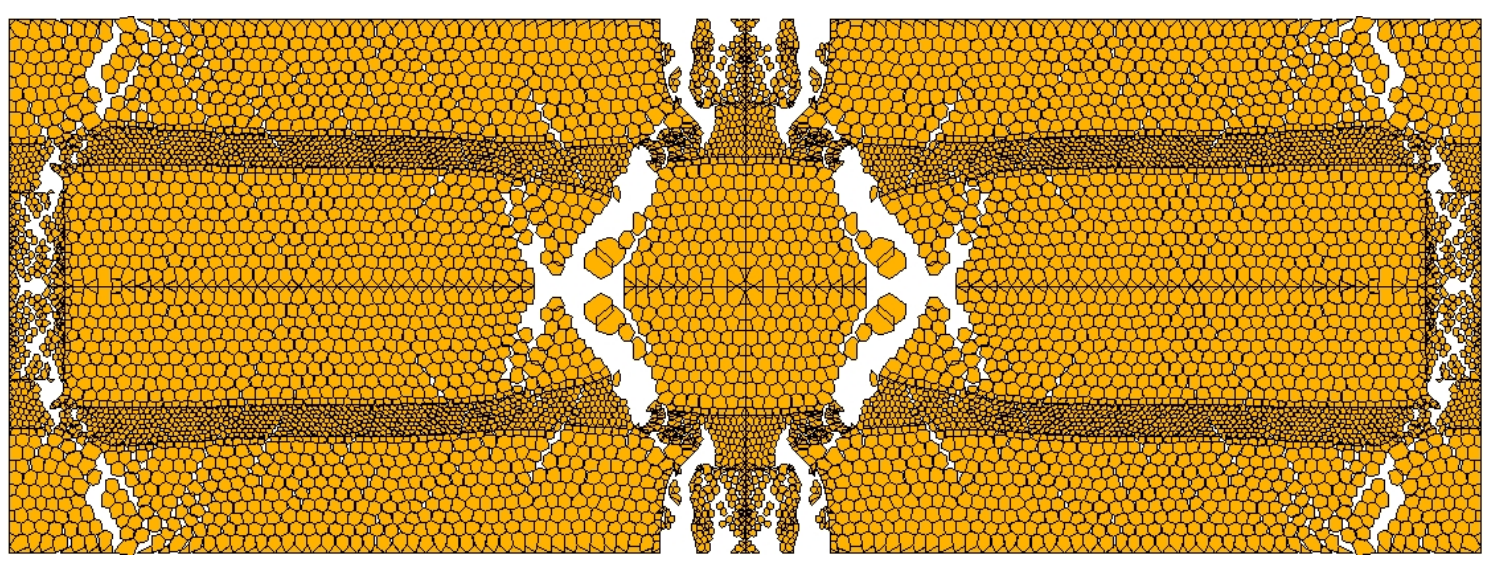

(a)

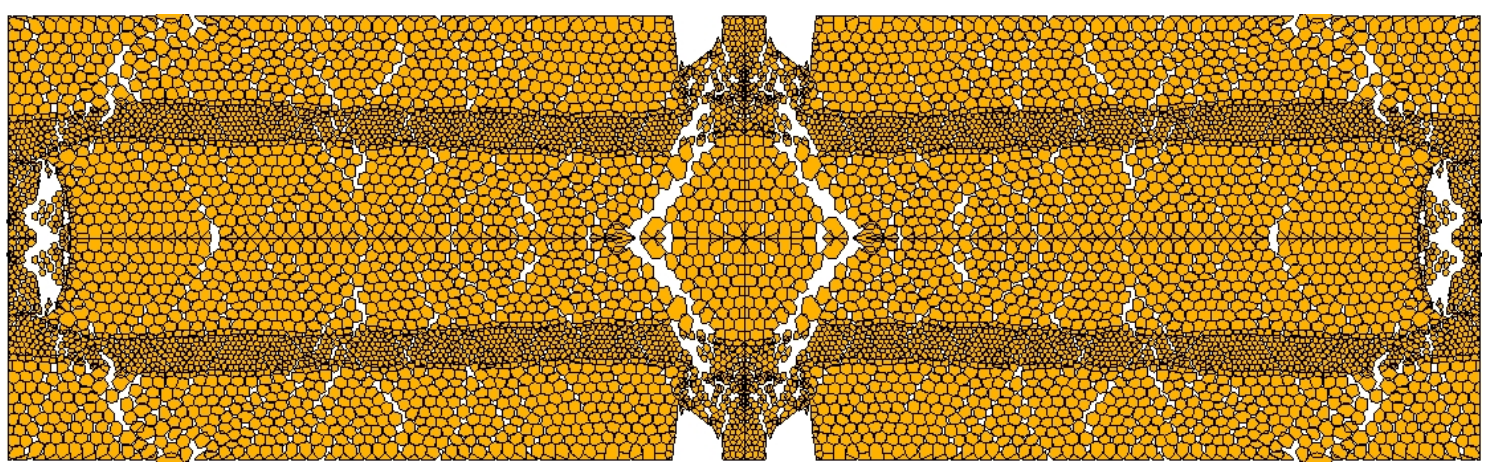

(b)

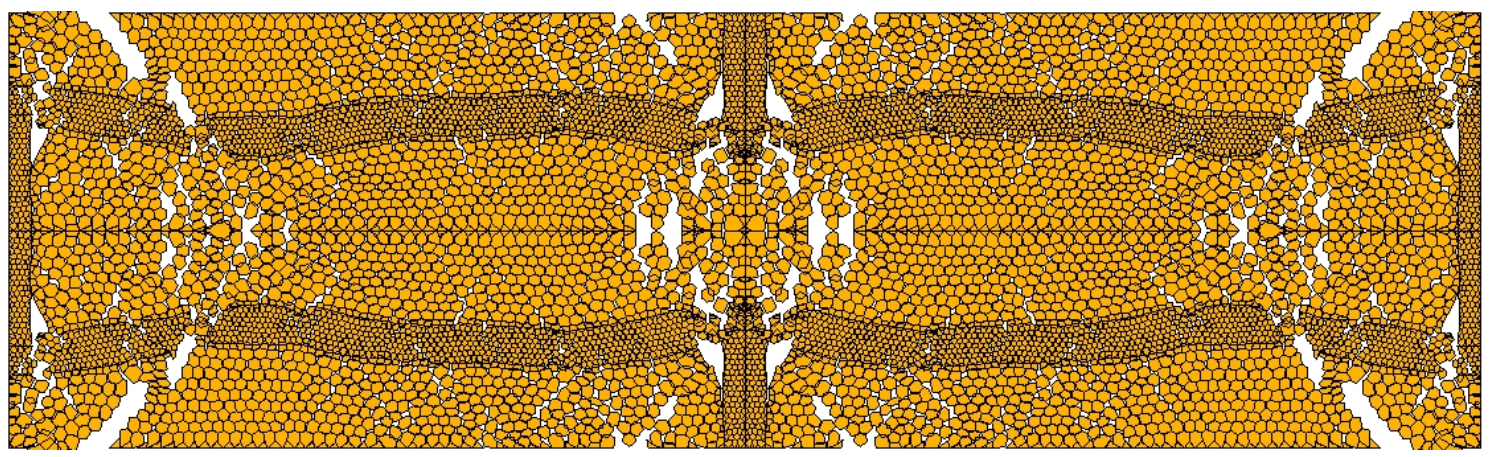

(c)

Figure 21 - Deformed (incremental) meshes near failure using the particle model for prisms: (a) P1, (b) P2 and (c) P3. 


\section{TABLES}

Table I - Elastic properties for the particles and interfaces.

\begin{tabular}{|c|c|c|c|}
\hline \multicolumn{2}{|c|}{} & $\begin{array}{c}\text { Average } \\
\text { values }\end{array}$ & $\begin{array}{c}\text { Coef. of } \\
\text { variation [\%] }\end{array}$ \\
\hline \multirow{2}{*}{ Particles } & $E$ & $5000 \mathrm{~N} / \mathrm{mm}^{2}$ & 30 \\
\cline { 2 - 4 } & $v$ & 0.15 & 0 \\
\hline \multirow{2}{*}{ Interfaces } & $k_{n}$ & $10^{4} \mathrm{~N} / \mathrm{mm}^{3}$ & 0 \\
\cline { 2 - 4 } & $k_{s}$ & $10^{4} \mathrm{~N} / \mathrm{mm}^{3}$ & 0 \\
\hline
\end{tabular}

Table II - Inelastic properties for the interfaces.

\begin{tabular}{|c|c|c|}
\hline & $\begin{array}{c}\text { Average } \\
\text { values }\end{array}$ & $\begin{array}{c}\text { Coef. of } \\
\text { variation [\%] }\end{array}$ \\
\hline$f_{t}$ & $1.0 \mathrm{~N} / \mathrm{mm}^{2}$ & 50 \\
\hline$G_{f I}$ & $0.050 \mathrm{~N} / \mathrm{mm}^{2}$ & 50 \\
\hline$c$ & $1.5 \mathrm{~N} / \mathrm{mm}^{2}$ & 50 \\
\hline$G_{f I I}$ & $0.75 \mathrm{~N} / \mathrm{mm}$ & 50 \\
\hline $\tan \phi$ & 0.30 & 50 \\
\hline
\end{tabular}

Table III - Average values from three analyses obtained for the compressive strength $f_{c}\left[\mathrm{~N} / \mathrm{mm}^{2}\right]$ according to different values of mesh refinement $M R$ and distortion factor $D F$ (values in brackets give the coefficient of variation).

\begin{tabular}{|c|c|c|c|}
\hline & $M R=n$ & $M R=2 n$ & $M R=4 n$ \\
\hline$D F=0$ & $12.0(10.4 \%)$ & $11.6(0.6 \%)$ & $12.0(6.7 \%)$ \\
\hline$D F=0.3$ & $10.9(15.4 \%)$ & $11.1(10.4 \%)$ & $11.6(3.3 \%)$ \\
\hline$D F=0.6$ & $9.9(15.3 \%)$ & $11.0(13.8 \%)$ & $11.4(8.4 \%)$ \\
\hline
\end{tabular}


Table IV - Average compressive strength $f_{c}$ from three analyses assuming different values for the interfaces tensile strength $f_{t}$. In brackets, the ratio against the reference bold value is given.

\begin{tabular}{|c|c|c|c|}
\hline & \multicolumn{3}{|c|}{$c=1.5 \mathrm{~N} / \mathrm{mm}^{2}$} \\
\hline$f_{t}\left[\mathrm{~N} / \mathrm{mm}^{2}\right]$ & $\mathbf{1 . 0}$ & $0.5(-50 \%)$ & $0.25(-75 \%)$ \\
\hline$f_{c}\left[\mathrm{~N} / \mathrm{mm}^{2}\right]$ & $\mathbf{1 1 . 1}$ & $9.9(-11 \%)$ & $9.2(-17 \%)$ \\
\hline
\end{tabular}

Table V - Average compressive strength $f_{c}$ from three analyses assuming different values for the interfaces cohesion $c$. In brackets, the ratio against the reference bold value is given.

\begin{tabular}{|c|c|c|c|}
\hline & \multicolumn{3}{|c|}{$f_{t}=1.0 \mathrm{~N} / \mathrm{mm}^{2}$} \\
\hline$c\left[\mathrm{~N} / \mathrm{mm}^{2}\right]$ & $\mathbf{1 . 5}$ & $0.75(-50 \%)$ & $0.37(-75 \%)$ \\
\hline$f_{c}\left[\mathrm{~N} / \mathrm{mm}^{2}\right]$ & $\mathbf{1 1 . 1}$ & $8.1(-27 \%)$ & $6.5(-41 \%)$ \\
\hline
\end{tabular}

Table VI - Average values from three analyses obtained for the tensile strength $f_{t}\left[\mathrm{~N} / \mathrm{mm}^{2}\right]$ according to different levels of mesh refinement $M R$ and distortion factors $D F$ (values in brackets give the coefficient of variation).

\begin{tabular}{|c|c|c|c|}
\hline & $M R=n$ & $M R=2 n$ & $M R=4 n$ \\
\hline$D F=0$ & $1.1(11.8 \%)$ & $1.1(9.8 \%)$ & $1.1(4.1 \%)$ \\
\hline$D F=0.3$ & $0.9(9.8 \%)$ & $1.0(7.6 \%)$ & $1.1(4.1 \%)$ \\
\hline$D F=0.6$ & $0.9(13.3 \%)$ & $1.0(1.1 \%)$ & $1.0(1.4 \%)$ \\
\hline
\end{tabular}

Table VII - Mechanical properties of the masonry components, (Binda et al., 1988).

\begin{tabular}{|c|c|c|c|c|}
\hline Component & $\begin{array}{c}E \\
{\left[\mathrm{~N} / \mathrm{mm}^{2}\right]}\end{array}$ & $\begin{array}{c}v \\
{[-]}\end{array}$ & $\begin{array}{c}f_{c} \\
{\left[\mathrm{~N} / \mathrm{mm}^{2}\right]}\end{array}$ & $\begin{array}{c}f_{f} \\
{\left[\mathrm{~N} / \mathrm{mm}^{2}\right]}\end{array}$ \\
\hline Unit & 4865 & 0.09 & 26.9 & 4.9 \\
\hline Mortar M1 & 1180 & 0.06 & 3.2 & 0.9 \\
\hline Mortar M2 & 5650 & 0.09 & 12.7 & 3.9 \\
\hline Mortar $M 3$ & 17760 & 0.12 & 95.0 & 15.7 \\
\hline
\end{tabular}


Table VIII - Mechanical properties of the masonry prisms, (Binda et al., 1988).

\begin{tabular}{|c|c|c|c|}
\hline Prism type & Mortar type & $\begin{array}{c}E \\
{\left[\mathrm{~N} / \mathrm{mm}^{2}\right]}\end{array}$ & $\begin{array}{c}f_{c} \\
{\left[\mathrm{~N} / \mathrm{mm}^{2}\right]}\end{array}$ \\
\hline$P 1$ & $M 1$ & 1650 & 11.0 \\
\hline$P 2$ & $M 2$ & 3835 & 14.5 \\
\hline$P 3$ & $M 3$ & 4565 & 17.8 \\
\hline
\end{tabular}

Table IX - Values assumed for the material parameters (in brackets, the coefficient of variation is given).

\begin{tabular}{|c|c|c|c|c|c|}
\hline \multicolumn{2}{|c|}{} & Unit & $M 1$ & $M 2$ & $M 3$ \\
\hline \multirow{3}{*}{ Particles } & $E\left[\mathrm{~N} / \mathrm{mm}^{2}\right]$ & $6000(30 \%)$ & $1500(30 \%)$ & $7000(30 \%)$ & $22000(30 \%)$ \\
\cline { 2 - 6 } & $v[-]$ & $0.09(0 \%)$ & $0.06(0 \%)$ & $0.09(0 \%)$ & $0.12(0 \%)$ \\
\hline \multirow{5}{*}{ Interfaces } & $k_{n}\left[\mathrm{~N} / \mathrm{mm}^{3}\right]$ & $1 \times 10^{4}(0 \%)$ & $1 \times 10^{4}(0 \%)$ & $3 \times 10^{4}(0 \%)$ & $8 \times 10^{4}(0 \%)$ \\
\cline { 2 - 6 } & $k_{s}\left[\mathrm{~N} / \mathrm{mm}^{3}\right]$ & $1 \times 10^{4}(0 \%)$ & $1 \times 10^{4}(0 \%)$ & $3 \times 10^{4}(0 \%)$ & $8 \times 10^{4}(0 \%)$ \\
\cline { 2 - 6 } & $f_{t}\left[\mathrm{~N} / \mathrm{mm}^{2}\right]$ & $3.40(45 \%)$ & $0.75(45 \%)$ & $3.50(45 \%)$ & $10.50(45 \%)$ \\
\cline { 2 - 6 } & $G_{f I}\left[\mathrm{~N} / \mathrm{mm}^{2}\right]$ & $0.170(45 \%)$ & $0.038(45 \%)$ & $0.175(45 \%)$ & $0.525(45 \%)$ \\
\cline { 2 - 6 } & $C\left[\mathrm{~N} / \mathrm{mm}^{2}\right]$ & $5.10(45 \%)$ & $0.30(45 \%)$ & $0.70(45 \%)$ & $15.75(45 \%)$ \\
\cline { 2 - 6 } & $G_{f I I}\left[\mathrm{~N} / \mathrm{mm}^{2}\right]$ & $2.55(45 \%)$ & $0.15(45 \%)$ & $0.35(45 \%)$ & $3.15(45 \%)$ \\
\cline { 2 - 6 } & $\tan \phi[-]$ & $0.10(45 \%)$ & $0.00(0 \%)$ & $0.00(0 \%)$ & $0.10(45 \%)$ \\
\hline
\end{tabular}

Table X - Numerical response obtained for the masonry components

(in brackets, the coefficient of variation is given).

\begin{tabular}{|c|c|c|c|c|}
\hline & Unit & $M 1$ & $M 2$ & $M 3$ \\
\hline$f_{c}\left[\mathrm{~N} / \mathrm{mm}^{2}\right]$ & $27.2(2.7 \%)$ & $3.2(5.0 \%)$ & $12.7(5.4 \%)$ & $95.8(4.4 \%)$ \\
\hline$f_{t}\left[\mathrm{~N} / \mathrm{mm}^{2}\right]$ & $3.61(1.4 \%)$ & $0.64(4.7 \%)$ & $2.70(4.2 \%)$ & $11.62(6.6 \%)$ \\
\hline$E\left[\mathrm{~N} / \mathrm{mm}^{2}\right]$ & $4786(1.9 \%)$ & $1309(1.4 \%)$ & $5632(3.0 \%)$ & $17176(3.1 \%)$ \\
\hline
\end{tabular}


Table XI - Adjusted stiffness values $E^{*}$ for the mortar.

\begin{tabular}{|c|c|c|c|c|}
\hline \multirow{2}{*}{ Mortar type } & \multirow{2}{*}{$\begin{array}{c}\text { Continuum } \\
\text { model }\end{array}$} & \multicolumn{3}{|c|}{ Particle model } \\
\cline { 2 - 5 } & $E\left[\mathrm{~N} / \mathrm{mm}^{2}\right]$ & $E\left[\mathrm{~N} / \mathrm{mm}^{2}\right]$ & $k_{n}\left[\mathrm{~N} / \mathrm{mm}^{3}\right]$ & $k_{\mathrm{s}}\left[\mathrm{N} / \mathrm{mm}^{3}\right]$ \\
\hline$M 1$ & 355 & 355 & $10^{4}$ & $10^{4}$ \\
\hline$M 2$ & 735 & 750 & $10^{4}$ & $10^{4}$ \\
\hline$M 3$ & 1065 & 1200 & $10^{4}$ & $10^{4}$ \\
\hline
\end{tabular}

Table XII - Experimental results Exp and numerical results using experimental Num_E and adjusted Num_E* mortar stiffness values.

\begin{tabular}{|c|c|c|c|c|c|c|c|}
\hline \multicolumn{2}{|c|}{} & \multicolumn{3}{|c|}{ Continuum model } & \multicolumn{3}{c|}{ Particle model } \\
\hline \multicolumn{2}{|c|}{ Prism type } & $P 1$ & $P 2$ & $P 3$ & $P 1$ & $P 2$ & $P 3$ \\
\hline \multirow{3}{*}{$f_{c}\left[\mathrm{~N} / \mathrm{mm}^{2}\right]$} & Exp & $\mathbf{1 1 . 0}$ & $\mathbf{1 4 . 5}$ & $\mathbf{1 7 . 8}$ & $\mathbf{1 1 . 0}$ & $\mathbf{1 4 . 5}$ & $\mathbf{1 7 . 8}$ \\
\cline { 2 - 8 } & Num_E & 19.8 & 24.2 & 31.0 & 15.5 & 19.3 & 30.8 \\
\cline { 2 - 8 } & Num_E & 18.2 & 24.1 & 30.0 & 15.4 & 17.3 & 24.6 \\
\hline \multirow{3}{*}{$\varepsilon_{p}\left[10^{-3}\right]$} & Exp & $\mathbf{1 0 . 5}$ & $\mathbf{7 . 9}$ & $\mathbf{6 . 6}$ & $\mathbf{1 0 . 5}$ & $\mathbf{7 . 9}$ & $\mathbf{6 . 6}$ \\
\cline { 2 - 8 } & Num_E & 10.6 & 9.7 & 8.4 & 5.4 & 4.6 & 6.2 \\
\cline { 2 - 8 } & Num_E* & 19.9 & 16.0 & 33.5 & 11.8 & 8.1 & 8.9 \\
\hline
\end{tabular}

